Revista de Estudios Histórico-Jurídicos

[Sección historia de las instituciones]

XLI (Valparaíso, Chile, 2019)

[pp. $527-559]$

\title{
LA CORTE, LOS VALIDOS, PRIVADOS SECRETARIOS Y CONSEJEROS EN LA HISTORIOGRAFÍA JURÍDICA Y POLÍTICA DE LOS SIGLOS XVI Y XVII
}

[The court, the favourites, private secretaries and counsellors in the legal and political historiography of the XVI and XVII centuries]

\author{
Marina Rojo Gallego-Burín* \\ Universidad de Granada, España
}

\section{RESUMEN}

Los tratados jurídico-políticos de la Edad Moderna constituyen una fuente primaria a la que es imprescindible acudir para estudiar de la burocracia de la época, un tiempo que se caracterizó por lo fructífero que fue en la impresión de libros de contenido jurídico y político. Gran parte de ellos fueron elaborados por miembros de la burocracia y los convirtieron en un medio para expresar su opinión y valoración, en ocasiones crítica, de la realidad. En aras de contribuir al estudio de la modernidad, en este trabajo analizamos diversos tratados para descubrir la perspectiva que tenían sus autores sobre la Corte, los validos, privados y otros miembros de la burocracia.

\section{Palabras Clave}

Literatura-Edad Moderna-Corte - privados - validos - secretarios.

\section{Abstract}

The legal-political books of the Modern Age are an essential primary source essential to study the bureaucracy of the time, a time that was characterized by the impression of many books devoted to politics and law. Most of the books were written by members of the administration and turned them into a means to express their opinion and valuation, sometimes critical. We have the purpose of contributing to the study of modernity and we will analyze various treaties to discover the perspective they provide on the court, the valid, private and other members of the administration.

\section{KeYwORDS \\ Literature -- Modern age - court - private - valid - secretaries.}

RECIBIDO el 24 de marzo de 2018 y ACEPTADO el 17 de diciembre de 2018

*Doctora en Ciencias Jurídicas por la Universidad de Granada (España). Universidad de Granada. Facultad de Derecho.marogabu@ugr.es 


\section{LA CIENCIA JURÍDICA EN LA EDAD MODERNA}

En primer lugar, nos debemos cuestionar ¿cómo se concibe la ciencia política en los siglos XVI y XVII? Murillo Ferrol indica que la ciencia política tiene dos sentidos: el clásico, que cuenta con implicaciones morales y se entiende como el conocimiento que posee el gobernante para llevar a cabo su ejercicio, dirige las acciones y concibe las cosas políticas como problemas prácticos que precisan de una solución. Y, por otra parte, el "conjunto de conocimientos sobre una esfera de la realidad" ", este sentido cuenta con un carácter exclusivamente intelectual; lo político es concebido como el objeto de conocimiento, sobre el que se especula. Por tanto, la primera acepción se sitúa en el ámbito del entendimiento práctico y la segunda en el de la especulación.

En el siglo XVII la ciencia política, aunque perduren reminiscencias de la Escolástica, considera a la política como una sección de la Teología moral o de la ética, que tiende a la especulación. En palabras de Murillo Ferrol: "Ciencia política es ante todo, aquel saber que tiene o debe tener el gobernante para manejarse en su oficio: un saber orientado y justificado por su aplicación inmediata en la vida, un saber práctico" ${ }^{2}$.

Asimismo, es destacable el tacitismo, una compleja doctrina que influyó en una amplia variedad de textos de todo género a lo largo de la modernidad. Para entender esta corriente hay que partir de que uno de los principales desafíos de la época o "caballo de batalla" , como ha afirmado Gil Pujol, era armonizar la política con la moral, y el rey con la ley. Adviértase que Maquiavelo defendía la independencia de la política respecto a la religión y la moral; y Bodino ${ }^{4}$ propugnaba que el rey es neutral en relación al derecho, está por encima de este y, por tanto, no está obligado por él. Entre mediados del siglo XVI y principios del XVII se enfatiza la animosidad contra las ideas del filósofo francés y sus partidarios. Rechazar este tipo de ideario era respetuoso con la posición oficial de la monarquía, pues en aquel entonces el reino era profundamente católico. Por tanto, expresar cualquier opinión contraria a ello, como hacían Maquiavelo o Bodino, era tremendamente osado y más aún si tenemos en cuenta que la Monarquía de los Austrias era un adalid de la Contrarreforma, y la obra de Maquiavelo es condenada por Paulo IV e incluida en el índice de los libros prohibidos 5 .

${ }^{1}$ Murillo Ferrol, Francisco, Saavedra Fajardo y la politica del Barroco (Madrid, Instituto de Estudios Políticos, 1957), p. 59.

${ }^{2}$ Murillo Ferrol, Francisco, Saavedra Fajardo cit. (n. 1), p. 60.

${ }^{3}$ Gil Pujol, Xavier, La razón de Estado en la España de la Contrarreforma. Usos y razones de la política, en La razón de Estado en la España Moderna (Valencia, Publicaciones de la Real Sociedad Económica del país, 2000), pp. 41 y 42.

${ }^{4}$ Tomás y Valiente afirmó, en relación a Jean Bodino, que: "Es difícil precisar hasta qué punto los escritores del siglo XVII son deudores directos de Bodino (a quien sin duda todos han leído, pero al que citan pocos". Véase Tomás y VALIENTE, Francisco, El gobierno de la monarquía y la administración de los reinos en la España del siglo XVII, en Historia de España, Ramón Menéndez Pidal, XXV: La España de Felipe IV (Madrid, Ed. Espasa-Calpe, 1982), pp. 1-214, maxime p. 37.

${ }^{5}$ Tierno Galván, Enrique, El tacitismo en las doctrinas politicas del Siglo de Oro, en Anales de la Universidad de Murcia, Murcia, 4 (4º trimestre 1948), pp. 805-988, maxime p. 913. 
Esta situación antimaquiavelista, tuvo una consecuencia inmediata y es la existencia de escritores que no son capaces de expresar abiertamente su apoyo a las teorías de Maquiavelo. La forma habitual, para manifestar la adhesión a las ideas maquiavélicas sin enfrentarse a la postura oficial, era enmascarar las opiniones valiéndose de Tácito ${ }^{6}$. Moralejo, traductor de Tácito, ofrece una definición muy concisa y esclarecedora de este fenómeno: "El perfil de Tiberio que traza en la primera héxada de los Anales se toma como prototipo de la astucia política, del proceder según la razón de estado, en la versión depurada y ortodoxa de Maquiavelo que es el tacitismo" . O también definido como el "redescubrimiento de las ideas políticas de Tácito, pero pasadas por el tamiz de otras doctrinas políticas y filosóficas", tales como Maquiavelo, Séneca o el cristianismo ${ }^{8}$.

Debemos considerar otras opiniones como las de Maravall o Murillo Ferrol, para quienes el utilizar a Tácito para ocultar a Maquiavelo es una "interpretación demasiado simplista", aunque algunos tratadistas se valieron de la obra de Tácito con esa finalidad, otros lo emplearon por su modo de conocer la realidad política, aunque como afirma Murillo Ferrol ello también suponía aproximarse a Maquiavelo, sin la p e 1 i g r o s i d a d moral e intelectual de este. No obstante, independientemente de esto, el tacitismo es una manifestación del empirismo político?

\section{LITERATURA POLÍTICA DEL BARROCO}

En los albores del siglo XVII los males que acechaban a la Monarquía se conjugaban con una atmósfera de júbilo, alborozo, cultura, reprobación y recomendaciones. Fue la época de esplendor de los arbitristas, eran numerosos los tratados que denunciaban la decadencia del imperio y, a la vez, ofrecían posibles soluciones a las causas de ello. Unos con auténticos dislates y otros con juiciosas proposiciones, pero todos con una misma finalidad: realizar una reforma política ${ }^{10}$.

José Antonio Maravall ${ }^{11}$ apreció que las obras políticas del siglo XVII cuentan con aspectos comunes, estos van desde sus características formales hasta el contenido, basta hojear estos tratados para apreciarlo. Comparten la apariencia: sus portadas tienen una misma disposición, el título de la obra, habitualmente redactado con la retórica barroca de la época, a continuación, el nombre del autor con los cargos y dignidades que ostente, tras él, el de la persona a la que se dedica, el impresor y año de publicación.

${ }^{6}$ Tomás y Valiente, Francisco, El gobierno de la monarquía, cit. (n. 4), p. 24.

${ }^{7}$ Moralejo Álvarez, José Luis, Introducción, en Tácito, Historias (Madrid, Akal, 1990), p. 22.

${ }^{8}$ Villalba Álvarez, Joaquín, La presencia de Tácito en los Anales de quince días, de Francisco de Quevedo. Una visión tácita de España, en Norba. Revista de Historia, 17 (2004), pp. 205-223, maxime p. 207.

${ }^{9}$ Murillo Ferrol, Francisco, Saavedra Fajardo, cit. (n. 2), p. 151.

${ }^{10}$ Domínguez Ortiz, Antonio, Tres milenios de historia (Madrid, Marcial Pons, 2001), p. 159.

${ }^{11}$ Maravall, José Antonio, La teoría española del Estado en el siglo XVII (Madrid, Instituto de Estudios Políticos, 1944), pp. 20 ss. 
A diferencia de los tratados jurídicos, los de contenido político se redactaban en castellano.

En lo concerniente al estilo literario de los tratados jurídico-políticos de la modernidad, en ellos abunda el empleo de recursos literarios tales como metáforas, alegorías, comparaciones... No por ello se puede considerar a todos los escritores que empleaban estos recursos literarios de culteranos. Pues a una gran mayoría de ellos se les podría aplicar el mismo adjetivo que Lope de Vega le censuraba a Jáuregui: teñidos. Se trata de personajes que en cierto modo se dejaron teñir por el cultismo, se vieron arrastrados y arrollados por el barroquismo. Nótese que muchos de los tratadistas de los siglos XVI y XVII se encuentran a caballo entre el naturalismo quinientista y el barroquismo seiscientista ${ }^{12}$. En consecuencia, ciertos tratados no emplean un lenguaje erudito, debido a que no se trata de obras destinadas en exclusiva a un pueblo docto. No obstante, aunque pueda apreciarse un ánimo, por parte de los autores, de emplear un lenguaje natural y asequible, sin duda, se trata de unas obras revestidas del espíritu Barroco. Además, manifiestan el pensamiento que caracteriza a este movimiento: el escepticismo, el desengaño y el pesimismo, utilizando asimismo los tópicos barrocos procedentes de la filosofía clásica: la fortuna, el teatro del mundo, tramoya, rueda de la fortuna...

La mayoría de los escritores de este tipo de discursos, aunque habitualmente tenían estudios superiores, no forman parte del profesorado de la Universidad. A pesar de ello, existen excepciones como la de Andrés Mendo, lector de teología y de Sagrada Escritura en Salamanca; Tovas y Valderrama, profesor en la Universidad de Alcalá; el P. Márquez o el doctor Sancho de Moncada, catedrático de Sagrada Escritura. Frecuentemente, los tratadistas son burócratas, tal es el caso del licenciado Gerónimo de Zebayos, regidor de Toledo; Mateo Lisón y Biedma, procurador en Cortes y Juan Fernández Abarca, contador. También encontramos letrados, como Martín González de Cellorigo o Francisco Bermúdez de Pedtraza; además de militares, secretarios o embajadores. Tanto por la formación, como por los cargos que ostentan estos autores poseen un acertado conocimiento de la realidad. Otro gran grupo de escritores, que dedicaron su atención a la literatura política, son los pertenecientes al estamento eclesiástico; poseían instrucción en cuestiones morales y, además, una fuerte influencia sobre el gobierno del Estado. En este grupo son representativos el obispo Antonio de Guevara, fray Juan de Santa María o el jesuita Pedro de Ribadeneyra. Dada la condición de burócratas de la mayoría de ellos sus obras resultan un testimonio en primera persona de la burocracia de los Austrias.

Asimismo, uno de los rasgos principales de este tipo de literatura es que tienen una finalidad práctica, actuar como un revulsivo, y que sus destinatarios: el monarca, los consejeros, los ministros, los vasallos... llevaran a cabo las reformas propuestas $^{13}$.

\footnotetext{
${ }^{12}$ MenéndeZ Pidal, Ramón, El P. las Casas y Vitoria con otros temas de los siglos XVI y XVII (Madrid, Espasa-Calpe, 1966), pp. 110 ss.

${ }^{13}$ Véase sobre este asunto: Rojo Gallego-Burín, Marina, La literatura jurídico-política castellana y portuguesa de los siglos XVI y XVII, en Revista Jurídica Universidad Autónoma de Madrid, 33 (2016), pp. 233-249.
} 
El interés que los escritores políticos manifiestan por los oficiales de la monarquía tiene su razón de ser en el hecho de estar enfrentándose a una nueva realidad. Con los Reyes Católicos y el Estado moderno, los burócratas, letrados y expertos del gobierno y de la administración sustituyen a los religiosos y aristócratas en los oficios -tanto los más preeminentes como los más técnicos-, lo cual supuso que la hidalguía, la erudición y la experiencia, entendida de un modo indefinido, dejara de ser el requisito imprescindible para ejercer tales funciones ${ }^{14}$. Y aunque si nos aproximáramos al reinado de Felipe II, comprobaríamos lo enrevesado de su clase política en la que confluían caballeros, letrados, religiosos, o legos, es en el siglo XVII cuando, como afirma Bennassar, se produce "el reto más grave", "el reto del valido o privado, del favorito único en quien delega la realidad del poder" ${ }^{15}$. Por ello, afirma el historiador francés que estos escritores, son los portavoces de esos letrados y facciones políticas que se han visto desposeídos de su poder.

\section{LA CORTE EN LA LITERATURA DEL SIGLO DE ORO}

¿Cómo es la corte, durante las centurias del siglo XVI y XVII?

En primer lugar, nos tenemos que plantear qué es la Corte. Es conveniente definirla, a fin de precisar a lo que nos vamos a referir. Las Partidas, le otorga un doble significado. Por una parte, el lugar físico y, por otra, las personas que ostentan el poder 16: "el lugar do es el Rey, e sus vasallos e sus oficiales con el, que le han cotidianamente de consejar e de servir, e los omes del reyno que se llegan y o por honrra del o por alcançar derecho, o por fazer lo o recabdar las otras cosas que han de ver con el. E tomó este nome de vna palabra de latín, que dizen cohors, en que muestra tanto como ayuntamiento de compañas. Ca alli se allegan todos aquellos que han a honrrar e de guardar al rey, e al reino. E otrosi ha nome en latin curia, que quere tanto dezir como lugar do es la cura de todos los fechos de la tierra ca alli se ha de catar, lo que cada vno deue auer, según su derecho, e su estado. Otro si es dicho corte, según lenguaje de España, porque alli es la espada, de la justicia, con que se han de cortar todos los malos fechos, tambien de dicho, como de fecho, asi como los tuertos, e las fuerças, e las soberuias que fazen los omes, e dizen".

Esta definición de las Partidas la incluye Covarrubias en su Tesoro de la lengua ${ }^{17}$.

${ }^{14}$ García Marín, José, La burocracia castellana bajo los Austrias (Sevilla, Ediciones del Instituto García Oviedo, Universidad de Sevilla, 1976), p. 83 y Maravall, José Antonio, Estado moderno y mentalidad social, siglos XV a XVII (Madrid, Ediciones de la Revista Occidente, 1972), II, pp. 443 ss.

${ }^{15}$ BennasAR, Bartolomé, La monarquía española de los Austrias. Conceptos, poderes y expresiones sociales (Salamanca, Universidad de Salamanca, 2006), p. 31.

${ }^{16}$ Part. 2, 9, 27.

${ }_{17}$ "Corte, quando sinifica el lugar, donde reside el Rey. Està declarada su etimología por la ley 27, titulo 9 de la partida segunda, que dize assi: [...]. De donde consta traer su origen de la palabra cohors, Militum manus, à conhortando dicha quòd Tribunus eam, vt sequatur hortari solear, seu quod ipsa se mutuo frequenter ad pugnam hortetur. Tambien pudiera decirse à cohaerendo, por el vnirse y apiñarse los soldados vnos con otros en el esquadron quando han de pelear. A quien no le fue bien en la Corte le parecio se auia dicho assi por corta, y que acorta la vida. Casos de Corte los de las viudas y pupilos y otros, contenidos en las leyes destos Reynos, Alcaldes de la casa y Corte del 
Además, el eclesiástico Fernández Navarrete se refirió también al vocablo Corte, aunque pueda ser discutible su apreciación, del que decía que había que ponderar en él: "la etimología de la palabra [...], como dixo la segunda Synodo Romana, se toma desta palabra Cruor, que significa sangre, porque lo mas que en las Cortes se platica, mira a carne y sangre" 18 . Pero con anterioridad se refirió a esta palabra del siguiente modo: "No inmerito el que le puso el nombre la llamo corte: porque en la corte delos principes todas las cosas son cortas, sino las malicias y embidias que son largas. El que no ha gustado el reposo de su casa, ni ha gustado el reposo de su casa, ni ha gustado el tumulto dela corte, aquel procura y desea entrear en la corte, que el que ya sabe a que sabe aquella yda: sospira quando la llaman, y llora si le detienen"19. Por su parte, en el libro compuesto por Núñez de Castro, se hace mención a la amalgama de connotaciones que implicaba esta palabra de Corte, su vinculación con la justicia, con los Consejos de Estado: "Algunos quieren que se dixesse Corte, de los filos de la espada, frequente simbolo de la Iusticia, y por tener esta en las Cortes su mas ilustre Trono en sus Tribunales, y ser los filos deste azero la gala mas bien parecida en el Principe, y que à vna le concilia mas amor, y respeto, juzgaron que auia tomado la Corte el nombre de la Iusticia, ó por los Tribunales, o por la misma persona del Principe. [...] Otros quieren que se llamasse Corte, de el nombre Latino Cohors, que significa junta de esquadrones militares; no porque sean frequentes en las Cortes las batallas, sino porque de sus Consejos de Guerra baxan los decretos, para quando se han de dar ó no, y assi les atribuyen, no solo las batallas sino también los triunfos, no sin alguna razón, porque como no se dan à las manos la alabanza de lo que obran, sino á la cabeça que las gobierna, por tener en ella su sitial razón, assi quien aconseja, se lleva los aplausos, no menos el que los executa. Otros confunden el nombre Corte, con el Latino Cohors; porque dizen hacen las Cortes soldados, haciendo los hombres pundonosos; y en la Guerra no son las fuerças mayores de el cuerpo las que batalllan, mejor sino los brios de el espiritu, y los espiritus de la honra. [...] Pretendieron otros, que se dixesse Corte, porque acorta la vida, hallándose en los Cortesanos, sobre el titulo de naver, nueva imposición para el morir: en el vivir mas dichoso, y al parecer mas

Rey. Dixe criminales, porque principalmente se ocupan en castigar delitos, y limpiar la Corte de la gente vagabunda y ruin, aunque juntamente conocen de las causas ciuiles. Cortesano, el que sigue la Corte, siruiendo al Rey, y porque se presume que los tales son muy discretos y auisados, llamamos Cortesanos a los que tienen bueno y hidalgo termino, y honrado trato. Cortesana, la muger libre, que en la guerra seguí la cohorte: lo qual era permitido por euitar mayor mal; de alli les quedó el nombre de cortesanas a las que en la Corte viuen licensiosamente, vnas mas que otras, por admitir gentes de diuersos estados y calidades". Véase De Covarrubias Orozco, Sebastián, Tesoro de la lengva casteñana. Española. Compvesto por el Licenciado Don..., Capellan de su Magestad, Maestrescuela y Canonigo de la Santa Yglesia de Cuenca, y Consultor del Santo Oficio de la Inquisición. Dirigido a la Magestad Catolica del Rey Don Felipe III nuestro señor. (en Madrid, con privilegio, por Luis Sanchez, impressor del Rey N. S., Año del Señor, 1611), f. 243 r.

${ }^{18}$ Fernández Navarrete, Pedro, Conservación de Monarquías y Discursos politicos sobre la gran consulta que el Consejo hizo al Señor Rey don Filipe Tercero al presidente, y Consejo Supremo de Castilla (Madrid, en la Imprenta Real, 1626), p. 177.

${ }^{19}$ Fernández Navarrete, Pedro, Aviso de privados y doctrina de cortesanos. Compuesto por el Illustre y Reverendisimo señor don..., Obispo de Mondoñedo, Predicador, y Chronista y del Consejo de su Magestad. Es obra muy digna de leer, y aun muy necessaria de a la memoria encomendar (en Pamplona, impresso con licendia de su magestad, por Thomas Parralis, 1579), f. $24 \mathrm{r}$. 
hidalgos del común tributo, que pagan los villanos à los afanes. [...] Otros con gran verisimilitud juzgaron que se llamava Corte, porque la suma diversión, y la variedad de ocupaciones de los Cortesanos, haze que parezcan cortos todos los días. [...] Otros juzgaron, que se llamò Corte, por ser la población, en que asisten los Consejos Supremos, y los hombres en todo linaje de noticias mas eminentes, con cuyo discurso se dàn cortes varios en los negocios importantes de la Religion, de la Guerra, de la Paz, y de todas las demás materias de Estado" 20 .

Estas definiciones ponen de manifiesto que el concepto de Corte había evolucionado, ya no era concebida como se hacía en el siglo XIII, sino que se trataba del centro que albergaba las instituciones que regían la Monarquía ${ }^{21}$. El siglo XVII no sólo va a contemplar una evolución del concepto de Corte, sino que incluso el comportamiento de los cortesanos se transforma. Este fenómeno se aprecia desde 1534, cuando Boscán traduce al castellano Il Cortegiano de Castiglione, sobre el perfecto castellano. Asimismo, fueron publicadas obras como el Galateo españo 22 -impresa más de veinte veces a lo largo de las centurias de los siglos XVII y XVIIIen la que se indica el modo de comportamiento de los palatinos en diferentes ámbitos, como en ceremonias, conversaciones... Además, el humanismo supuso toda una metamorfosis en la actitud de los palaciegos para adaptarse a la situación política del momento, poniendo su acento en el lenguaje y la elocuencia, que era lo que otorgaba al hombre su dignidad y cultura ${ }^{23}$.

En la primera mitad del siglo XVI también es destacable la obra Menosprecio de Corte, que publicara en la ciudad de Valladolid el año de 1539, el obispo de Mondeño y cronista Antonio de Guevara. Esta obra constituye una sátira a la vida cortesana, es un canto a la defensa de la vida en el campo. Se ha definido como: "un retrato de una sociedad conflictiva escrito con un ingenioso y acomodaticio sentido del humor capaz de apelar a un público igualmente ambivalente y heterogéneo" 24 . En esta aguda crítica encontramos afirmaciones como: "Tiene la Corte vn no sé què, un no sè donde, vn no sè como, y un no te entiendo, que cada dia hace que nos quexemos, que nos alterèmos, que nos despidamos, y que por otra parte no nos dà licencia para irnos" 25 . La Corte se presenta como un lugar pernicioso,

\footnotetext{
${ }^{20}$ NúNÉz de CASTRo, Alonso, Libro histórico politico, solo Madrid es Corte, y el cortesano en Madrid (Madrid, por Domingo García Morrás, 1669), pp. 1-5.

${ }^{21}$ Martínez Millán, José, Introducción. La Monarquía de Felipe III: Corte y Reinos, en Martínez Millán, José y Visceglia, María Antonietta (dirs.), La monarquía de Felipe III: La Casa del Rey (Madrid, Fundación Mapfre, Instituto de Cultura, 2008), p. 49.

${ }^{22}$ Gracián Dantisco, Lucas, Galateo español (Madrid, Luis Sanchez, 1599).

${ }^{23}$ Martínez Millán, José, Introducción, cit. (n. 21), pp. 59 y 60.

${ }^{24}$ Rabell, Carmen R., Menosprecio de corte y alabanza de aldea: ¿crítica lascasiana, propaganda imperialista o "best-seller"?, en Actas Irvine-92 [Actas de XI Congreso de la Asociación Internacional de Hispanistas] (Madrid, 1994), pp. 245-253.

${ }^{25}$ De Guevara, Antonio, Menosprecio de Corte, y alabanza de aldea, en el qual se tocan muchas, y muy buenas doctrinas, para los hombres que aman el reposo de sus casas, y aborrecen el bullicio de las Cortes, copilado por el Illmo. Y Rmo. Sr. Don..., Obispo de Mondoñedo, Predicador, y Choronista y del Consejo de su Magestad. Dirigido al muy alto y Poderoso Rey de Portugal, Don Juan el Tercero deste nombre. Quinta impression. Con licencia (en Madrid, por Juan Valentino, año de 1735), p. 123.
} 
cuyos cortesanos hacían de ella un pésimo lugar social, donde prima la ambición, la falsedad, el vicio y donde la fortuna era un factor relevante: "En la Corte vna qualquiera que quiere ganar de comer à ser truhan, ò loco, ò chocarrero, no solo no es por ello reprehendido, ni castigado, mas aun es de muchos socorrido, y de todos favorecido. En la Corte vna doncella, ò una viuda, vna descasada ò vna mal casada que quiere ser ramera, ò cantonera, no avrá vno que la reprehenda de su mal vivir, y avrà ciento que la vayan à recuestar" 26 ; "QQué vida, qué fortuna, qué gusto, ni qué descanso puede tener vno en Palacio, viéndose alli entre tantos vendido?" 27.

Brancalasso en Nápoles a comienzos del siglo XVII dedica un libro a la Corte, continuando con la tónica vista hasta ahora. Asevera que "Todas son cortas las cosas en las Cortes, sino es la maldad, y la bellaquería que es perpetua y nunca se acaba" 28 . Presenta a la Corte como un laberinto, un lugar del que es difícil salir, por ello su objetivo es dar las claves al privado y cortesano para que pueda huir de ese lugar. Bajo un propósito de mejora de la realidad, traza lo que se necesita para fundar una Corte, sostiene que bastaban dos condiciones: aire saludable y mantenimiento bastante ${ }^{29}$. Pero ello, ¿qué significa? Vale decir que para gozar de una vida saludable es necesario respirar un aire de buena calidad y que este sea constante, lo cual se traduce en que es preciso conocer las causas de corrupción, los remedios para purificar y el mantenimiento de este. En definitiva, Brancalasso hace un dibujo de como sería una Corte perfecta, en cuanto a sus habitantes, disposición y cuestiones de salubridad.

Adviértase que el cese de la itinerante corte, estableciéndose en un punto fijo, implicó en el siglo XVII una transformación de la burocracia y de la configuración urbanística de la ciudad. En esta época del Barroco se propaga la idea de una imprescindible reforma de la Corte. Felipe IV, en su primer acto político de 1621 manda constituir una nueva Junta de Reformación de la Corte y del Reino, ya que la decadencia del reino ocasiona la de la Corte.

En este marco político, esa necesidad de reformación va a tener su reflejo en las letras, se convierte en un tema abordado por diversos autores tales como Cristóbal Pérez de Herrera que le dedicó dos tratados, Martín González de Cellorigo en su Memorial de la política necesaria y útil restauración a la república de España (1600), Sancho de Moncada en Restauración política de España (1619) o Martínez de la Mala en Memoriales y discursos (1650).

Incluso la literatura picaresca hablaba de la decadencia de la Corte, la ma-

${ }^{26}$ De Guevara, Antonio, Menosprecio de Corte cit. (n. 25), p. 111.

${ }^{27}$ Ibíd., p. 122.

${ }^{28}$ Brancalasso, Julio Antonio, Libro Labirinto de Corte con los diez predicamentos de cortesanos. Dos libros en los quales estan comprehendidos todos los bienes, y males que pueden, y suelen acontecer en las Cortes de Principes à los que sigue. Y se dan diferentes modos de salir felizmente del Laberinto para gloria de Dios, y con honras, y riquezas del mundo, como tambien para fundar vna Corte Real. Con los avisos necesarios para ganar, conseruar la gracia de los mesmos Principes, y de todos los generos de personas que en qualquiera manera tratan con ellos. Resumidos de los Autores politicos Catholicos que hastagora han escrito en materia de estado, y de buen gouierno. Por el Doctor..., sacerdote natural de la Ciudad de Tursi. Vn tomo llamado Labirinto de Corte (Nápoles, por Juan Bautista Gargano y Lucrecio Nucci Empressores, 1609), p. 11.

${ }^{29}$ Ibíd., p. 95. 
yoría de las novelas de este género se desarrollan en Madrid, la ciudad-mundo, la Babilonia. Ejemplos ilustrativos son El Buscón de Francisco de Quevedo y Los peligros de Madrid de Baptista Remiro de Navarra de $1646^{30}$. Asimismo, se pueden mencionar tratados dedicados a advertir los peligros de la Corte, como el de Liñán y Verdugo ${ }^{31}$ o Gracián ${ }^{32}$.

El cronista Gil González Dávila en 1623 afirma cómo debía "ser su poderosa Corte, y madre de la policía Christiana; maestra de las mejores costumbres, y asiento de la prudencia y consejo. Altas consideraciones, que obligan mucho à la corte à no admitir en si propia excessos, ni demasias, viuiendo con admirable templança, enseñando con su virtud, y modestia à las demas ciudades de su Imperio el modo que han de guardar para acertar felizmente en el discurso de la vida humana"33.

El ilustre eclesiástico Pedro Fernández Navarrete (1564-1632) ${ }^{34}$, en sus obras se preocupó del estado de la Monarquía. En 1621 dio a la imprenta el opúsculo Discursos Políticos, que se convirtió en el germen de una obra de mayor envergadura: Conservación de Monarquías. Discursos políticos, sobre la que pretendemos fijar nuestra atención. Este es un tratado que aparece en 1626 y se integra de cincuenta discursos. A lo largo de sus 344 páginas se describe el estado de la Corte, en esos momentos. Nos dibuja una Corte que contaba con una excesiva población: " $L a$ que ay en esta Corte, es excessiua en numero, y assi es bien descargarla de much a parte de ella, y mandar à los que huuieren de salir, que se vayan a sus tierras". Defiende una "purga", "hacerle una sangría", como ya hubiera realizado tiempo atrás el emperador Carlos I. Aconseja que aquellos sujetos que habían acudido a la Corte "sin causa legítima" la abandonen, este era el caso del estamento nobiliario, las viudas y los eclesiásticos, a los que critica con dureza, algo llamativo dada la propia condición de religioso del autor: "Grandes y señores, y los Caualleros y gente desta calidad, y un numero grande que ay de viudas muy ricas y poderosas, y otras que no lo son tanto", "[...] y muchas personas Eclesiásticas, que teniendo obligación de residir en sus beneficios, so color de que tienen pleitos en esta Corte, y que sus Iglesias los embian a la defensa dellos, se vienen a ella, con que defraudan al culto Divino, a la residencia, y à las limosnas que hizieran, y deuieran hazer, si estuuieran tan asistentes al servicio de sus prebendas, como fuera razón". El que se descongestionara la Corte

${ }^{30}$ Caporosi, Olivier, La Babilonia del crimen o la nueva Roma de la policía cristiana: el discurso sobre la decadencia y la reformación de la Corte en la primera mitad del siglo XVII (15971645), en ARANDA PÉREZ; F. J. (coord.), La declinación de la monarquía hispánica en el siglo XVII (1597-1645) (Universidad de Castilla-La Mancha, 2004), pp. 845-861, maxime pp. 849 ss.

${ }^{31}$ LiñÁn y Verdugo, Antonio, Guia y avisos de forasteros, a donde se les enseña a huir de los peligros que ay en la vida de Corte; y debaxo de nouelas morales, y exemplares escarmientos, se les auisa, y aduierte de como acudirán a sus negocios cuerdamente, por el licenciado Don... (Madrid, con privilegio, por la viuda de Alonso Martin, 1620).

${ }^{32}$ Gracián, Baltasar, Óraculo manual y arte de prudencia (Madrid, CSIC, 1954).

${ }^{33}$ GonzÁlez Dávila, Gil, Teatro de las grandezas de la Villa de Madrid Corte de los Reyes Católicos de España (Madrid, 1623), p. 3.

${ }^{34} \mathrm{El}$ humanista y licenciado en cánones por la Universidad de Salamanca, Pedro Fernández Navarrete alcanzó la dignidad de canónigo de la Catedral de Santiago de Compostela. Véase GoN̄i GaZTambide, José, El licenciado Pedro Fernández Navarrete su vida y sus obras (1564-1632), en Berceo, 97 (1979), pp. 27-48. 
era con la finalidad de que se convirtiera en un lugar "más desenfadada, y sin tanta confusión, y aun sin tantos vicios, y ofensas de nuestro Señor". La situación social que se describe en este libro resulta dramática, Fernández Navarrete utiliza los adjetivos de holgazanes y facinerosos, que habían hecho de la Corte un lugar con gran experiencia en "enormes y feos delitos", "intratable i ingouernable". El problema poblacional es continuo en el libro, critica la presencia de los estamentos más preeminentes, pero también lo hace contra aquellas "personas de inferior gerarquia": lacayos, cocheros, aguadores, suplicacioneros, esportilleros, y abridores de cuellos. El autor utiliza calificativos severos: "quan fea, asquerosa, y deslustrada està la Corte con ellos”. Añade Fernández Navarrete, que debían además abandonar la Corte, sus numerosos pretendientes que contaba la Corte, cuestión en la que intervino el Consejo dictando que se concedieran los premios a aquellos que esperaran en su casa, para tratar de anular a los ambiciosos que de modo continuado están junto a monarcas y ministros; pues era conocimiento general que "en las Cortes de ordinario arrebatan los premios, no los mas solicitos, y los que tienen mas franca la entrada en los vltimos retretes de los Ministros" 35.

Saavedra Fajardo en su célebre Idea de un príncipe christiano se refiere también a la Corte y el problema poblacional que supuso el haber atraído a población de otros lares de la Monarquía: "La corte es causa principal de la despoblación, porque como el hígado ardiente trae a si el calor natural, y dexa flacas y sin espíritu las demás partes; asi la pompa de las cortes, sus comodidas, sus delicias, la ganancia de las artes, la ocasión de los premios tira á si la gente, principalmente á los oficiales y artistas, juzgando que es mas ociosa vida la de servir que de trabajar. Tambien los titulados, por gozar de la presencia del Principe y lucirse, desamparan sus estados, y asisten en la corte, con que no cuidando de ellos, y trayendo sus rentas para su sustento y gastos superfluos, quedan pobres y despoblados, los quales serian más ricos y mas poblados, si viviese en ellos el señor" 36 .

Dentro de la historiografía algunos autores fueron más allá y críticos con su contemporaneidad. Es el caso de Francisco Bermúdez de Pedraza (1576-1655) ${ }^{37}$, que en 1645 publica un libro titulado Hospital Real de la Corte. Cómo afirma Gil González Dávila, los hospitales tienen por objetivo: "cumplir con las obras de misericordia de curar a los enfermos, albergar al peregrino, y enseñar al que no sabe" 38 . Por eso la segunda parte del título de esta obra es de enfermos heridos del animo. Esto tiene su razón de ser en la situación que vivía la monarquía cuando esta obra ve la luz. Nótese que los años cuarenta del siglo XVII fueron frenéticos para la

\footnotetext{
${ }^{35}$ Por todo: Fernández Navarrete, Pedro, Conservacion de Monarqvias y Discursos politicos sobre la gran Consulta que el Consejo hizo al Señor Rey don Filipe Tercero al Presidente y Consejo Supremo de Castilla, por el Licenciado..., Canonigo del a Iglesia Apostolica de Señor Santiago Capellan y $S^{\circ}$ de sus Magestades y Altezas. Consultos del Santo Oficio de la Inquisicion (en Madrid, con privilegio, en la Imprenta Real Año, 1626), pp. 11-180.

${ }^{36}$ SaAvedra Fajardo, Diego, Idea de un príncipe politico-christiano por..., caballero de la Orden de Santiago (Valencia, en la Oficina de Salvador Faulí, Año 1801), II, p. 190.

${ }^{37}$ Véasen sobre este autor: Rojo Gallego-Burín, Marina, El pensamiento juridico y politico de Francisco Bermúdez de Pedraza (1576-1655) (Madrid, Marcial Pons, 2018).

${ }^{38}$ GonzÁlez Dávila, Gil, Teatro de las grandezas de la Villa de Madrid Corte de los Reyes Católicos de España (Madrid, 1623), p. 300.
} 
política, auspiciados desde la década anterior, con una Castilla pobre, un pueblo oprimido que despreciaba al valido por considerarlo arbitrario y dictatorial ${ }^{39}$. A lo que había que sumarle la situación bélica que vivía la casa de Austria ${ }^{40}$.

Este libro de Bermúdez se presenta como una alegoría, donde el hospital se funda en la Corte porque es donde abundan las fuerzas del mal, los vicios y hay más enfermos heridos de ambición, avaricia, soberbia, envidia y arrogancia. Esa "Piscina de la Corte, llena de miserias, dignas de misericordia". Describe Bermúdez la Corte como: "un resualadero de buenos, y un atolladero de malos; Es una Vniuersidad de vicios, vn Teatro de ambicion vna Plaça de auaricia, vn Mercado de Venus; y Domicilio de la gula; es vna Republica, donde la amistad es aparente, el favor mercenario; la gracia venal, y la desgracia mortal; y es vltimamente un Teatro donde el Historiador lisonjea, el Orador engaña, el Consejero adula, y todos tratan de su conueniencia; cada vno a su negocio; y los públicos, Dios los haga". "Es la Corte la plaça mas abundante de vicios, y de enfermos, mortalmente heridos de ambicion, $y$ de avaricia: señoras de muchos, y nobles vasallos" ${ }^{21}$. En el primer folio del tratado el autor se refiere a la Corte como una Babylonia ${ }^{42}$. Era un lugar donde reinaba el desconcierto, donde convivían cortesanos, burócratas, pretendientes, eclesiásticos, pleiteantes, soldados, escuderos, pajes, lacayos, vagabundos, mendigos, pícaros, ganapanes ${ }^{43}$... Evocar a la antigua Mesopotamia para referirse a la Corte no era una idea original de Bermúdez, así se habían referido a ella también otros autores de la época como Lope de Vega ${ }^{44}$, Quevedo ${ }^{45}$, Avellaneda ${ }^{46}$ o Gracián ${ }^{47}$. La razón por la que equiparar a Madrid con Babilonia nos la ofrece el propio Lope de Vega en uno de sus versos:

${ }^{39}$ Elliott, John, El Conde-Duque de Olivares (Barcelona, Editorial Crítica, 1991), pp. 543 ss.

${ }^{40}$ En 1640 la Casa de Austria lucha en tres guerras simultáneamente. El Imperio estaba en guerra con Suecia y Francia. La Monarquía Hispánica con la república de Holanda y con Francia y, aunque no había declaración oficial, de hecho también con Suecia. A lo que había que sumar la probable guerra con Cataluña o el golpe de Estado en Portugal, p. 572.

${ }^{41}$ Bermúdez de Pedraza, Francisco, Hospital Real de la Corte, por Don..., Canonigo y Tesorero de la Santa Iglesia de Granada. A D. Francisco Marin y Rodezno Canonigo de la S. I. de Toledo, Inquisidor de Granada (Granada, 1645), dedicatoria- f. 6v.

${ }^{42}$ Ibíd., f. 1v.

${ }^{43}$ ReY HAZAS, Antonio, Madrid: corte y literatura en la primera mitad del siglo XVII, en Martínez Millán, José y Visceglia, María Antonietta (dirs.), La monarquía de Felipe III: La Casa del Rey (Madrid, Fundación Mapfre, Instituto de Cultura, 2008), pp. 651-666, maxime p. 652.

${ }^{44}$ Lope de Vega en diferentes ocasiones se refirió a la Corte como Babilonia, como en sus Rimas afirma "Hermosa Babilonia en que he nacido”. O también “¡Oh, Babilonia del mundo,/ de lenguajes tan diversos!”. Véase De Vega y CARPIO, Lope, Rimas.

45 "A la villa de Madrid/ encomendé mis talones./ [...] Llegamos a Babilonia/ un miércoles por la noche”, DE QUEVEDO, Francisco, El parnaso español o las nueve musas castellanas.

46 "Madrid, donde por la Babilonia de la Corte, fácilmente se encubre y disimula cualquier desdichado".

47 "Esto dijo al entrar en una de sus más célebres ciudades, gran Babilonia de España, emporio de sus riquezas, teatro augusto de las letras y las armas, esfera de la nobleza y gran plaza de la vida humana”, Gracián Lorenzo, Obras de..., tomo primero que contiene El Criticón, primera, segunda, y tercera parte: $y$ el Heroe (en Madrid, en la Imprenta de Pedro Marin, año de 1773), p. 51. 


\section{¡Adios Babilonia ilustre, \\ Querida y amada patria, archivo donde se encierran del mundo naciones varias ${ }^{148}$}

Parece así reafirmarse la idea de que el término Madrid etimológicamente procede probablemente de madre de todos ${ }^{49}$. Y es que la sociedad de Madrid desde que se convirtió en Corte su sociedad era heterogénea, diversa, y plurinacional. Era cosmopolita, en ella residía un gran número de extranjeros, y convivían diferentes nacionalidades. Además, Lope añade el calificativo de a r c h i v o, contaba con un orden, una jerarquía ${ }^{50}$.

En este punto podemos reproducir un diálogo, entre Andrenio y Critilio, que escribe Gracián en el célebre Criticón, que pese a ser una novela se trata de una de las obras más superiores del barroco español. Pasaje en el que se aúnan las ideas vistas anteriormente y en el que por su expresividad se refleja a la perfección los sentimientos antagónicos que llegaba a suscitar la Corte: "A vistas estaba ya de la Corte, y mirando Andrenio à Madrid, con fruición grande: preguntóle el Sabio: ¿qué ves en quanto miras? Veo (dijo él) una real madre de tantas naciones, una corona de dos mundos, un centro de tantos Reynos, un joyel de entrambas Indias, un nido del mismo Fenix, y una esfera del Sol Catholico, coronado de prendas en rayos, y de blasones en luces. Pues yo veo (dijo Critilo) una Babilonia de confusiones, una Lutecia de unmundicias, una Roma de mutaciones, un Palermo de volcanes, un Constantinopla de nieblas, un Londres de pestilencias, y un Argel de cautiverios. Yo veo (dijo el Sabio) à Madrid, madre de todo lo bueno, mirada por una parte, y madrastra por la otra; que asi como à la Corte acuden todas las perfecciones del mundo, mucho mas todos los vicios, pues lo que vienen à ella nunca traen lo bueno, sino lo malo de sus patrias" ${ }^{51}$.

A mediado del siglo XVII, 1658, Núñez de Castro publica Libro histórico político, solo Madrid es Corte, y el cortesano en Madrid. Un tratado al que ya nos hemos referido con anterioridad, pero cuyo valor estriba en que está dedicado exclusivamente a la Corte y sus cortesanos y es redactado por el cronista de Felipe IV. En este libro además de describir la Corte destaca una instrucción que debía seguir todo aquel que pretendiera ser un perfecto cortesano. En dicha guía dictaba los vicios de los que debía huir quien deseara alcanzar aplausos de cortesanos, para lo cual expide un total de diez dogmas políticos, tales como huir del ocio y ser una persona instruida, versada tanto en ciencias como en historia, geografía, con conocimientos lingüísticos, y amplio vocabulario, e indica ciertos

${ }^{48}$ De Vega y Carpio, Lope, Los mártires de Madrid.

${ }^{49}$ Deleito y Piñuela, José, Sólo Madrid es Corte. La capital de dos mundos bajo Felipe IV (Madrid, Espasa-Calpe, 1963), p. 13.

${ }^{50}$ Rivero Rodríguez, Manuel, Los Consejos territoriales, en Martínez Millán, José y Visceglia, María Antonietta (dirs.), La monarquía de Felipe III: La Casa del Rey, (Madrid, Fundación Mapfre, Instituto de Cultura, 2008), pp. 372-434, maxime pp. 372 y 373.

${ }^{51}$ Gracian Lorenzo, Obras de Lorenzo Gracian. Tomo primero que contiene El criticon, primera, Segunda y Tercera parte: Y el Heroe, (en Madrid, en la Imprenta de Pedro Marin, año de 1773, a costa de la Real Compañía de Impresores y Libreros de el Reyno), pp. 131 y 132. 
conocimientos que es mejor que desconociera como los arbitristas. En cuanto a la filosofía, defendía que bastaba con que supiera lo preciso para que no se dijera que la ignora. Asimismo, el libro tercero de su libro bajo el título De la voluntad, lo dedica al comportamiento del cortesano. El primero de los dogmas que se requiere es el de la cortesía, el estudio de la urbanidad resulta el de mayor utilidad, y que fuera un buen católico. El tercer dogma se encuentra bajo el epígrafe "contra la torpeza”, en él defiende que los cortesanos mantuvieran una vida casta; el propio autor reconoce que este dogma no iba ser seguido, pero declaraba "el peligro" que suponían las mujeres y más las de Madrid, resultaba cierto. Además, presenta a la corte como un lugar mentiroso, los cortesanos llegaban a ser "esclavos de la mentira”, también deberían velar por la educación de sus hijos, la elección de las amistades, cuyo acierto resulta dificultoso y peligroso y peligrosísimo su yerro, y el cuidado con la indumentaria, la glotonería y la bebida ${ }^{52}$.

\section{El REFLEJO DE LOS VALIDOS Y PRIVADOS EN LA LITERATURA JURÍDICO-POLÍTICA} DE LA MODERNIDAD

Durante los siglos XVI y XVII, como signo de nepotismo empiezan a aparecer linajes de validos, hasta el punto de crearse una auténtica r e v o l u c i ó n d e 1 i n a j es, desaparece la promoción dentro de la burocracia y se incorporan hombres que no habían seguido el cursus honorum tradicional. Durante el gobierno de estos validos creció la corrupción de una manera extraordinaria, ocasionando el declive de aquella justicia real que llegó a sus cotas más altas con los Reyes Católicos.

Esta institución, que fue odiada por el pueblo, en cierto modo servía para salvaguardar a la monarquía, pues las críticas se dirigían hacia el valido y no contra el rey ${ }^{53}$.

Ello nos explica que a partir de mediados del siglo XVI aparezca un género literario nuevo, que se ocupa del análisis de las instituciones, así como los requisitos y las cualidades deseables para aquellos que las integraban. Son tiempos en los que se reiteran las obras referidas a secretarios, privados o embajadores ${ }^{54}$.

Esto mismo fue apreciado por García Marín, respecto a los integrantes de la administración, la manera de referirse a ellos varía según el tratadista ${ }^{55}$, e incluso

${ }^{52}$ Núnez De Castro, Alonso, Libro histórico político cit. (n. 20), pp. 279-337.

${ }^{53}$ Elliott, John, El Conde Duque de Olivares, sociedad y Estado en el siglo XVII, en Historia (1979), pp. 52 ss.

${ }^{54}$ Maravall, José Antonio, Estado moderno y mentalidad social, cit. (n. 14), p. 456.

${ }^{55}$ Los tratadistas barrocos no seguían ningún criterio uniforme para referirse a estos miembros de la Corte, pero ya en nuestra contemporaneidad, Tomás y Valiente llevó a cabo la que calificó como nada fácil tarea de diferenciar a los ministros y los oficiales, Así calificaba de ministros a aquellos que "ocupan los principales puestos en el gobierno político de la monarquía. En ellos predomina lo político sobre lo administrativo". Los oficiales "domina la competencia técnica, el conocimiento profesional, la pericia administrativa". Y entre ambos hay una amplia zona intermedia compuesta por consejeros no togados, y los oficiales titulares de los "oficios de justicia". Véase Tomás y Valiente, Francisco, Las instituciones situadas en el ámbito de la monarquía, en 
puede suscitar cierta confusión, pero esta solo es superficial, ya que en definitiva "todos ellos se refieren a una misma realidad" 56.

Es necesario hacer referencia a las obras y los escritores que aludieron a privados, validos, secretarios o consejeros, aquellos que expresamente analizan esa figura. Aunque autores como García Marín, Tomás y Valiente o Maravall, han hecho referencia a algunas de ellas en sus trabajos, es preciso analizar el contexto literario imperante. Estos escritores los conjugaremos con el ambiente político que se vivía en esos momentos, pues sin ello no se comprende el porqué de estas obras.

El siglo XVI ve aparecer los libros de cortesía o de formación de cortesanos, cuya obra más representativa es Il Cortegiano de Baldassare Castiglione, a la que nos referimos con anterioridad, en ella el autor describe aquellas condiciones, virtudes y cualidades que debe reunir el cortesano ${ }^{57}$. Cinco años después de que esta obra se tradujera al castellano, en 1539, Antonio de Guevara publica, en la ciudad de Valladolid, Avisos de privados y doctrina de cortesanos dedicada al secretario del emperador Carlos I, Francisco de los Cobos, y de la que se harían sucesivas impresiones. De esta obra Tomás y Valiente destaca no tanto su finalidad didáctica, como que el autor se adelanta aproximadamente un siglo a la literatura del barroco ${ }^{58}$. Guevara concibe su libro como un testimonio sincero, sin incurrir en la lisonja; en él expone al monarca diez recomendaciones a cerca de cómo debe ser el privado. Y resalta el valor de los consejos que dan las personas doctas, y el peligro de que estos sean proporcionados por "truhanes"; añora los tiempos pretéritos: "cotejados los tiempos pasados, con los presentes, parecenos a los que algo avemos leydo, que aquellos era fina grana, y estos mala polilla [...], aquellos dias claro, y estos nublado, porque ya en las cortes de los principes, y en las casas de los grandes señores, mas se precian de tener un truhan que los regocije, que no a un hombre, sabio que los aconseje" 59 .

Con Felipe II, como rey de Castilla, continúa imperando esta temática en la literatura, aunque sería con su hijo cuando apareciera el primer valido, el nieto de los Reyes Católicos contó con consejeros privados como Moura, Veleda, Chinchón e Idiáquez. En 1559, El Concejo y consejeros del Príncipe del valenciano Fadrique Furió Ceriol ${ }^{60}$, es publicado en Amberes. La obra de Ceriol alcanzó una enorme

Historia de España, Ramón Menéndez Pidal, XXV: La España de Felipe IV (Madrid, EspasaCalpe, 1982), pp. 156 y 157.

${ }^{56}$ GARCía Marín, José, La burocracia castellana bajo los Austrias, cit. (n. 14), pp. 86 y 87.

${ }^{57}$ Feros, Antonio, El Duque de Lerma. Realeza y privanza en la España de Felipe III (Madrid, Marcial Pons, 2002), p. 84.

${ }^{58}$ Tomás y Valiente, Francisco, Los validos en la monarquía española del siglo XVII. Estudio institucional ( $1^{\text {a }}$ ed., Madrid, Instituto de Estudios Políticos, 1963; Madrid, Siglo Veintiuno de España Editores, 1990), p. 128.

${ }^{59}$ De Guevara, Antonio, Aviso de privados, y doctrina de Cortesanos. Compuesto por el Illustre $y$ Reuerendissimo señor don..., Obispo de Mondoñedo, Predicador, y Choronista, y del Consejo de su Magestad. Dirigido al Illustre señor don Francisco de los Cobos, Comendador mayor de Leon, del consejo de estado de su Magestad. Dirigido al Illustre señor don Francisco de los Cobos, Comendador mayor de Leon, del consejo de estado de su Magestad, (Barcelona, Hieronymo Margarit, 1612), ff. $86 \mathrm{v}$ y $87 \mathrm{r}$.

${ }^{60}$ Furió Ceriol, Fadrique, El Concejo y consejeros del Príncipe. Obra de..., que es el libro 
celebridad, circuló por todo el continente europeo, fue múltiples veces reimpresa y traducida a otras lenguas como el latín, el inglés, francés o el polaco. Furió Ceriol es un valenciano considerado por sus estudiosos como un precursor, que tuvo la pretensión de conformar un ideario que no tuviera una trascendencia meramente local sino universal. Se le considera como un predecesor de Montesquieu, se dice de él que "desde el siglo XVI Fadrique Furió Ceriol ha sido reconocido como uno de los pensadores españoles más originales y provocadores del mundo de la teoría política y en otros campos de la actividad humanista" ${ }^{61}$. Su pensamiento se caracteriza por la originalidad, sus argumentaciones y razonamientos son al margen de la religión, ni Dios ni los padres de la Iglesia son empleados como argumento de autoridad, sus discursos destacan por no utilizar una s e l v a de autoridades, como argumento de autoridad. "Furió Ceriol está tan lejos del platonismo como del catolicismo español del siglo XVI, y de él puede decirse que rompió con su tiempo tanto como es posible imaginar" ${ }^{62}$. Pero la doctrina discrepa, en cuanto al sentido de su tratado, si bien para algunos como M. Baitllon, esta es una obra descriptiva de la monarquía de Felipe II, para otros, como Mochoulan, constituye una dura crítica tanto a la organización como a la ideología político-religiosa del momento. En cuanto al contenido de este libro, una de sus partes más relevantes es la dedicada a las calidades que necesita el consejero del soberano, las cuales divide en dos, las que precisa en cuanto al alma y en cuanto al cuerpo. Respecto de las del alma detalla que es necesario que el consejero sea "de alto i raro ingenio", "que sepa las artes de bien hablar", "que sepa muchas lenguas", "grande historiador", "que sepa bien i perfetamente el fin, la materia, el como, el quanto, i hasta quanto se estienda cada virtud", "que sea político", "haver andado i visto muchas tierras", "que sepa las fuerças i poder de su principe", "que no solamente ame el bien publico, pero que en procurarlo, se olvide de su propio provecho i reputación", "que sepa curar todo el cuerpo del principado", "que sea justo y bueno", "que sea franco y liberal”, "que sea amigo de hazer el bien", "que sea manso i afable" y "que sea fuerte". Respecto de las calidades del cuerpo Furió Ceriol especifica que el consejero requiere "que ni tenga menos de treinta años, ni passe de los sesenta", que "sea sanguino, o colérico", "de mediano talle en el altor i grossura", "de buena proporcion en todas las partes del cuerpo", "bien carado, i de buena gracia".

De estas obras percibimos una idea preponderante: el rey necesita consejo. Esta concepción, que la veremos reiterarse en otros muchos tratados, provocó en el hijo del emperador cierta controversia: compatibilizar la presencia de sus adeptos y fieles sin que colisionaran con las camarillas políticas. Esta peliaguda cuestión la subsanó el monarca creando un organismo, que le asesorara en la toma de decisiones y haría las veces de tutor del heredero: la Junta de Gobierno, también conocida como Consejo Privado, en $1584^{63}$.

primero del quinto Tratado dela institución del Principe, (Amberes, en casa de la Biuda de Martin Nucio, 1559).

${ }^{61}$ BleznICK, Donald W. Los conceptos politicos de Furio Ceriol, en Revista de Estudios Politicos, 149 (1966), pp. 25-46, maxime p. 44.

${ }^{62}$ Furió Ceriol, Fadrique, El Concejo y consejeros del Príncipe, cit. (n. 60), p. 49.

${ }^{63}$ Feros, Antonio, El Duque de Lerma, cit. (n. 57), pp. 68 y 69. 
En estos tiempos es publicada otra obra política, el Tratado del Consejo y de los Consejeros de los príncipes, compuesta por el doctor Bartolomé Felippe y publicada en el reino de Portugal, en Coimbra, en el año de 1584, y que Francisco de Quevedo califica de "doctísimo tratado" ${ }^{64}$. Como discípulo de Furió Ceriol, Bartolomé Felippe aborda la misma temática que este, del consejo y sus consejeros. Sin embargo, a lo largo de sus diecisiete discursos plantea problemáticas como la de la sucesión en el reino de Portugal, y expresa su adhesión a que el rey Felipe sucediera en el reino ${ }^{65}$, pues a él le correspondía conforme a derecho ${ }^{66}$.

Pocos años después, en 1587, comenzaba el declive del cargo del secretario del rey, los sucesores del secretario Juan de Idiáquez, se verán ensombrecidos por los miembros de la Junta y los consejeros de Estado más influyentes ${ }^{67}$.

De tal modo, que nos aproximamos a la última década del siglo XVI, década en la que el Marqués de Denia, al no ver mejorada su situación económica, idea una nueva táctica. Gómez de Sandoval no solicita ayuda a Felipe II, sino que pone sus objetivos en el heredero, sobre el que comenzará a ejercer una fuerte influencia. Esta se hace tan evidente que consejeros como Cristóbal de Moura recomiendan al hijo del emperador que nombren al marqués de Denia virrey de Perú. El consejero no logra que el destino de Sandoval sea Perú, pero sí consigue que lo nombren virrey de Valencia, a donde se traslada en 1595, un modo de exilio. Sólo dos años más tarde el duque estaba de regreso en la Corte ${ }^{68}$, cuando en la primavera de 1597 Felipe II ya no podía ocuparse de todos sus deberes, estaba en el ocaso de su vida, y había delegado algunas de sus responsabilidades en su hijo ${ }^{69}$. Era un momento muy propicio para el regreso del marqués.

En esta década, en el año de 1592, el maestro y prior del monasterio de San Agustín, Marco Antonio Camos publica en Barcelona Microcosmia y Gobierno Universal del Hombre christiano, para todos los estados y qualquiera de ellos; que dedicó al embajador de España en Roma y duque de Sessa y Soma, Antonio de Cardona. Es una obra original en cuanto a su estructura, pues, aunque aborda cuestiones políticas, como hacen otras, lo hace en forma de diálogo.

A lo largo de estas pláticas se tratan asuntos como los referentes a los criados del rey, ellos son encuadrables en diferentes géneros, como los que tratan los negocios del monarca, de sus estados y de su casa. Dentro de esta tipología se incluye entre otros, a los consejos, sus presidentes, y los secretarios, especialmente el de

${ }^{64}$ De Quevedo, Francisco, La política de Dios, capitulo XXI, edición utilizada: Obras de D. Francisco de Quevedo Villegas (Madrid, por D. Joachin Ibarra, 1752), III, p. 237.

${ }^{65}$ En las Cortes de Tomar (1580), Felipe II es reconocido rey de Portugal.

${ }^{66}$ Felippe, Bartolomé, Tractado del Consejo y delos consejeros delos Principes, compuesto por el Doctor...: Dirigido al muy alto y serenissimo señor Cardenal Alberto Legado y Archiduque Daustria, (Coímbra, impresso en casa de Antonio de Mariz impresor de la Vniversidad, 1584), f.10v.

${ }^{67}$ Escudero López, José Antonio, Los secretarios de Estado y del despacho (Madrid, Estudios de Historia de la Administración, Instituto de Estudios Administrativos, 1969), pp. 232 y 233.

${ }^{68}$ Williams, Patrick, El favorito del rey: Francisco Gómez de Sandoval y Rojas, V marqués de Denia y I duque de Lerma, en Martínez Millán, José y Visceglia, María Antonietta (dirs.), La monarquía de Felipe III: La Casa del Rey (Madrid, Fundación Mapfre, Instituto de Cultura, 2008), pp. 285-260, maxime p.193.

${ }^{69}$ Feros, Antonio, El Duque de Lerma, cit., (n. 57), p. 71. 
cámara, al que equipara con un "guardajoyas", pues en él residen "los mas altos y mas preciados tesoros que el Rey tiene que son sus secretos: en el sacramento y guarda de los quales consiste mucha parte del buen estado y gobierno del honor y reputacion del Rey y sus Reynos" $"$.

Cuando faltaban dos años para que el marqués de Denia regresara de su exilio a la Corte, el jesuita Pedro de Ribadeneyra publica en Madrid, una obra cuya influencia se haría patente en posteriores textos políticos de la monarquía moderna ${ }^{71}$ : Tratado de la religion y virtudes que debe tener el Principe Christiano, para gobernar y conservar sus Estados. Contra lo que Nicolas Maquiavelo y los Politicos deste tiempo enseñan ${ }^{72}$, dirigida al todavía príncipe Felipe. De este tratado se harían sucesivas impresiones también en Amberes y en el siglo XVII.

El propio título de esta obra desprende el rechazo que este autor sentía hacia las ideas de Maquiavelo, se trata de una obra inundada de doctrina cristiana, uno de los mayores exponentes de la teoría contractualista de la monarquía, que defiende el origen divino del poder que detenta el rey y que imperó a finales del siglo XVI. Riaza Martínez-Osorio encuadra al autor en la "falange antimaquiavelista" 73 , aunque sus críticas no se ciñen sólo al filosofo italiano, pues tampoco comparte las ideas de autores como Bodin.

Esta obra es publicada por vez primera en las postrimerías del reinado de Felipe II, cuando ya existía la honda preocupación de que su sucesor se encontraba influido por el marqués de Denia, de ahí la dedicatoria al príncipe. En ella, el jesuita afirma que en él recae toda la atención por todas las responsabilidades a las que se aproxima, y "por la turbación y calamidad de tiempos que corren por nuestros peccados, de heregias, y errores inventados por hombres amigos de si mismos, crueles, viciosos y desalmados". Para Ribadeneyra "la peor y mas abominable secta que Satanas ha inuentado, es vna de los que llaman Politicos. [...] Esta secta es tanto mas perniciosa, quanto su malicia es mas encubierta: porque halagando, máta, y con beso de falsa paz, quita la vida"74. Lo que constituye una severa advertencia al sucesor de Felipe II. Pero ello no es impedimento para mantener, como una exigencia

${ }^{70}$ De Camos, Marco Antonio, Microcosmia y Gobierno Universal del Hombre christiano, para todos los estados y qualquiera de ellos. Dirigido a Don Antonio de Cardona, Duque de Sessa y Soma, del Consejo del Rey nuestro Señor, y por su Magestad Embaxador de España en Roma. Va por Dialogos dividido en tres partes en la primera se trata de las Personas Reales, y de su gouierno de paz y guerra, consejos, y ministros. En la Segunda, del gouierno Politico, Magistrados, y Personas ocupadas en ellos: y de la Economia y estados a la Republica necesarios. En la Tercera y vultima dela Monarchia Ecclesiastica y Personas de ese estado, y Religioso. Compuesto por el maestro..., prior del Monasterio de S. Agustín de Barcelona. Con quatro Indices necesarios y copiosos (Barcelona, en el Monasterio de Sancto Agustin, por Pablo Malo, 1592), p. 119.

${ }^{71}$ Feros, Antonio, El Duque de Lerma, cit., (n. 57), p. 53.

${ }^{72}$ Ribadeneyra, Pedro, Tratado de la religion y virtudes que debe tener el Principe Christiano, para gobernar y conservar sus Estados. Contra lo que Nicolas Maquiavelo y los Politicos deste tiempo enseñan. Escrito por el P..., de la Compañía de Iesus. Dirigido al Principe de España D. Filipe nuestro señor (Madrid, en la emprenta de Plantiniana, 1597).

${ }^{73}$ Riaza Marínez-Osorio, Román, Historia de la literatura jurídica española, Madrid, 1930, en Interpretatio. Revista de Historia del Derecho Universidad Complutense de Madrid, 5 (1998), pp. 17-239, maxime p. 138.

${ }^{74}$ Ribadeneyra, Pedro, cit. (n. 72), dedicatoria al príncipe. 
de la monarquía, el servirse de consejeros. Aunque le exhorta a la precaución con los privados, la privanza es un "golfo peligroso"75. Ribadeneyra se propone probar que la privanza es algo aventurado, ello lo arguye con diversos sucesos históricos, como el de Federico II, a cuyo privado y secretario, Pedro de las Viñas entregó a sus enemigos, tras mandar sacarle los ojos. Son ejemplificaciones de lo voluble de los sentimientos. Tras lo cual se suceden los capítulos didácticos dirigidos al heredero, dedicados a cómo prevenirse de los lisonjeros, o cómo distinguir del falso al amigo verdadero.

A pesar de todas estas recomendaciones, consejos y avisos, Felipe II en septiembre de 1598 baja a la sepultura en El Escorial y la monarquía se aproxima a un nuevo sistema de gobierno, con Felipe III como monarca y el marqués de Denia convertido en duque de Lerma se alza con el poder.

Por otra parte, si tratamos de hallar precedentes políticos, en los comienzos del siglo XVII, es preciso hacer referencia a un fenómeno propio de los Austrias, que aunque surge en tiempos de Felipe II y se extendería hasta el último de la dinastía, será durante el reinado de Felipe III cuando surge con mayor auge, y por ello es considerado propio del Barroco. Nos referimos al arbitrismo ${ }^{76}$.

El Arbitrio, es un término polisémico, el significado que nos interesa es el que lo define como "una figura fiscal que reporta beneficios a corto plazo y no requiere negociar con los contribuyentes" 77 . De este término de arbitrio deriva la palabra arbitrista, que apareció en el ocaso del siglo XVI y son aquellos que se "dirigían a una autoridad para proponerle la ejecución de un nuevo arbitrio"78. Pues bien, esto que podía haber sido algo fructífero, el que se hicieran propuestas para subsanar los problemas hacendísticos de la monarquía, degeneró en un negocio. Los arbitristas requerían de una recompensa económica por la reforma propuesta.

Si nos aproximamos a los escritos de estos arbitristas comprobamos como sus proposiciones no eran solo impositivas, por ser la crisis tan generalizada también atendían a cuestiones políticas. Muestra de ello es el Memorial de la política necesaria y útil restauración a la República de España, y estados de ella y del desempeño universal de estos Reynos, del abogado de la real chancillería y del santo oficio de la inquisición Martín González de Cellorigo, calificado por Bennassar como "uno de los reformadores más atrevidos de su tiempo"79, esta obra es publicada en Valladolid cuando sólo habían transcurrido dos años de la llegada al trono de Felipe III, en 1600. En los más de sesenta folios que componen su memorial dedica parte de sus recomendaciones a los consejeros que rodean al monarca y le ayudan en la toma

\footnotetext{
${ }^{75}$ Ibíd., p. 432.

${ }^{76}$ Véase sobre este tema: GuTIÉRREZ NieTO, Juan Ignacio, El pensamiento económico, político y social de los arbitristas, en Historia de España Menéndez Pidal, XXVI (I): El siglo del Quijote (1580-1680). Religión filosofía, ciencia (Madrid, Espasa Calpe, 1986), pp. 235- 354; GARCíA Guerra, Elena María, Moneda y arbitrios. Consideraciones del siglo XVII (Madrid, Departamento de Publicaciones del Consejo Superior de Investigaciones Científicas, 2003).

${ }^{77}$ Dubet, Anne y Sabatini, Gaetano, Arbitristas: Acción politica y propuesta económica, en Martínez Millán, José y Visceglia, María Antonietta (dirs.), La monarquía de Felipe III: La Casa del Rey (Madrid, Fundación Mapfre, Instituto de cultura, 2008), pp. 867-869, maxime p. 867.

${ }^{78}$ Ibíd.

${ }^{79}$ Bennassar Bartolomé, La monarquía española, cit. (n. 15), p. 23.
} 
de decisiones. Advierte el jurista, tras exponernos una España en decadencia, que uno de los mayores peligros para el rey y su nación, es el confiar en aquellos que violan las "leyes de la buena política", lo embaucan y se suceden los equívocos. Debido a que los consejeros abordan cuestiones complejas en el gobierno de la monarquía; González Cellorigo advierte lo necesario que es rodearse de personas en los que la prudencia prime. ¿Pero qué está ocurriendo en el reino para que sea publicado un memorial como este? Ese mismo año de1600, era reformado el Consejo de Estado. El rey y su valido determinan su composición y lo configuran como el órgano supremo de gobierno ${ }^{81}$. A principios del siglo XVII, con Lerma en el poder, son numerosos los nombramientos que se producen en el gobierno, de hombres afines al valido. Es el modo de mantenerse el duque en el poder, deshacerse de los hombres de confianza de Felipe II, culpabilizándolos de la crisis y dirigiéndoles cruentas críticas. Felipe III desentendido del gobierno, y dominado por el valido, ignoró las recomendaciones que le había dado su padre: "y en la justicia y buen gobierno sereis amigo de consejo, y de tomar parecer de personas, que os le sepan dar con amor y verdad. Yo me hallo bien con D. Christobal de Moura y con los demás que traygo á mi lado en los negocios. Asi confio que os hallareis a vos, si os sabeis servir de él y de ellos"82.

A pesar de los cambios, la Monarquía se encuentra en crisis, se declarará en suspensión de pagos en 1607. Pero las vicisitudes no son sólo económicas, en 1611 se convierte en palmariamente política; el confesor del rey y el hijo del valido (fray Luis de Aliaga y el duque de Uceda, respectivamente) afianzan su coalición y gozan de un mayor protagonismo en el gobierno, lo cual va a desencadenar que la unidad de los hombres de Lerma se resquebraje ${ }^{83}$ y la corte se divida entre los partidarios de uno y otro.

Como escritor, en este periodo tenemos que destacar a Gabriel Pérez del Barrio Angulo, secretario del Marqués de Vélez y Alcayde de la fortaleza de su Villa de Librilla. En 1613 publica una obra titulada Dirección de Secretarios de Señores, y las materias, cuidados, y obligaciones que les tocan, con las virtudes de que se han de precisar, estilo, y orden del despacho y expediente manejo de papeles de ministros, formularios de cartas, provisiones de oficios y un compendio en razón de acrecentar estado, hazienda, oficio de Contador, y otras curiosidades que se declaran en la primera hoja. Es considerado como uno de los primeros "manuales de secretario", los cuales tenían una finalidad formativa para los secretarios de la época ${ }^{84}$. En su momento alcanzó un gran éxito, en 1622 y 1645 fue reimpresa, además él mismo afirma que

${ }^{80}$ Gonzáles de Cellorigo, Martín, Memorial de la política necesaria y útil restauración a la República de España, y estados de ella y del desempeño universal de estos Reynos. Dirigido al Rey Don Philippe III, nuestro señor. Por el Licenciado..., Abogado de la Real Chancilleria, y del Santo Officio de la ciudad de Valladolid (Valladolid, por Juan de Bostillo, 1600), f. $34 \mathrm{r}$.

${ }^{81}$ Williams, Patrick, El favorito del Rey, cit. (n. 68), p. 212.

${ }^{82}$ González Dávila, Gil, Monarquía de España. Historia de la vida y hechos del inclito monarca, amado y santo D. Felipe Tercero. Obra posthuma del maestro..., cronista de los Señores Reyes D. Felipe III y IV, y mayor de las dos Castillas y de las Indias. Publicala Don Bartholome Ulloa, mercader de libros (Madrid, por D. Joachin de Ibarra, 1771), p. 26.

${ }^{83}$ Feros, Antonio, El Duque de Lerma, cit. (n. 57), p. 377.

${ }^{84}$ Serrano Sánchez, Carmen, Cartas al Papa: modelos epistolares en los manuales de 
"fue tan bien recibido, que a pocos dias se desaparecio, y se traia de Napoles, Sicilia, y Valencia, donde fue impresso" 85 .

Pérez del Barrio sigue la estela de Castillo de Bobadilla, que se refirió al régimen señorial. En la Política para corregidores encontramos referencias a los secretarios, Castillo de Bobadilla detalló que los jueces se encontraban coaccionados por estos secretarios, ambicionando supremacía: " $Y$ según el tenue salario y estipendio que dan a los Jueces y de la manera que los tratan aún me maravillo que hallen quien los sirva, porque demás de estar sujetos a las parlerías de privados de los secretarios y otros criados que quieren tener mano en el gobierno y administración de justicia por sus intereses" $" 86$. Ello muestra el abuso de poder que estos secretarios ejercían, seguramente a consecuencia de la falta de regulación que tenía este cargo, lo cual le suscita a Pérez del Barrio la necesidad de redactar su tratado: "Viendo que por estar el oficio de secretario de señores, tan desnudo de estilo, orden, ni forma, se le atreve tanto la ignorancia, por no saber las muchas materias, u cuidados, cargas y obligaciones que le tocan, y que le han sido ingratos. [...] Vengo a ser el que pone las primeras piedras en tan gran edificio, conforme a nuestro estilo" ${ }^{87}$.

Pérez del Barrio alude a la necesidad de diferenciar entre los distintos oficios. Afirma la existencia de una variada tipología de secretarios, que se singularizan por la "diversidad de papeles e inclinaciones" ${ }^{8}$ : hay secretarios lisonjeros, otros virtuosos y otros secretarios veniales. Además, había "oficios que tienen usurpado el nombre y título de Secretario" 89 , nos expone como el término de secretario se había vulgarizado, otorgándolo en ocasiones a oficios que no les correspondía. Ello era consecuencia de que se atribuían la dignidad de secretario porque el género y ejercicio de su ocupación era el "de pluma". La causa de esta confusión,

correspondencia de los siglos XVI-XVII, en Via Spiritus. Revista de História da Espiritualidade e do Sentimento Religioso, 18 (2012), pp. 159-182, maxime p. 163.

${ }^{85}$ Pérez del Barrio Angulo, Gabriel, Secretario y Consegero de Señores, y Ministros; cargos, materias, cuidados, obligaciones, y curioso Agricultor de quanto el Gobierno, y la Pluma piden para cumplir con ellas: El indice las toca, y están ilustradas con sentencias, conceptos, y curiosidades no tocadas, 1639. Hemos utilizado la edición de Madrid, por Mateo de Espinosa, 1667, dedicatoria al lector.

${ }^{86}$ Castillo de Bovadilla, Jerónimo, Politica para Corregidores, y Señores de Vassallos, en tiempo de paz, y de guerra. Y para Juezes Ecclesiasticos y Seglares y de Sacas, Aduanas, y de Residencias, y sus Oficiales: $y$ para Regidores, y Abogados, y del valor de los Corregimientos, y Goviernos Realengos, y de las Ordenes, Autor el Licenciado..., del Consejo del Rey Don Felipe III nuestro Señor, y su Fiscal en la Real Chancilleria de Valladolid (en Amberes, en casa de Iuan Bautista Verdussen, Impressor y Mercader de Libros, 1704 [1ª ed., Madrid, 1597], edición facsímil, con Estudio preliminar por Benjamín González Alonso, Instituto de Estudios de Administración Local, Madrid, 1978).

${ }^{87}$ Pérez del Barrio Angulo, Gabriel, Direccion de Secretarios de Señores, y las materias, cvydados, y obligaciones que les tocan, con las virtudes de que se han de preciar, estilo, y orden del despacho y expediente, manejo de papeles de ministros, formularios de cartas, prouisiones de oficios, y vn compendio en razon de acrecentar estado, y hazienda, oficio de Contador, y otras curiosidades que se declaran en la primera hoja. Por..., Secretario del Marques de los Velez, y Alcayde de la Fortaleza de su villa de Librilla. Dirigido al Marques de Cañete don Iuan Andres Hurtado de Mendoça (en Madrid, por Alfonso Martin de Balboa año 1613), folio sin numerar, dedicatoria al marques de Cañete.

${ }^{88}$ Ibíd., f. 1v.

${ }^{89}$ Ibíd., f. 1 r. 
a la hora de atribuir tal epíteto a oficios que no les corresponde, Pérez del Barrio la atribuye a la Pragmática de cortesías promulgada por Felipe $\mathrm{II}^{90}$, que dio lugar a toda una problemática entorno a estas cuestiones. En definitiva secretarios del rey eran los del Consejo de Estado, Guerra, Cámara y Mercedes y aquellos que, anteponiendo el mandato real, refrendan reales cédulas y despachos. Es a ellos a quienes les corresponde recibir lo elaborado por los escribanos de cámara, para que lo firme el monarca, lo refrenden ellos y los escribanos lo remitan a las partes. Pero esta cuestión solo aparece en la primera impresión de 1613, desapareciendo en las sucesivas.

En esta obra, además, a lo largo de los libros que la componen encontramos aspectos teóricos, como establecer las virtudes que debe contar el secretario, o las dieciséis particularidades del oficio, como el de los caminos de la privanza y peligros de ella. Pérez del Barrio años más tarde volvería a publicar esta obra introduciendo en ella novedades, el tratado pasa a denominarse Secretario y Consegero de Señores y Ministros, siguiendo las pautas del consejero Pedro de Contreras y el maestro Gil González Dávila, que le recriminaron el no haberle otorgado ese mejor título en la primera edición de la obra. En este tratado vuelve a resaltar la grandeza del Secretario pues es una figura que todos buscan: reyes, príncipes, señores y ministros; este secretario y consejero "es tan importante Ministro, que con su ayuda se lleva el peso de los mayores cuidados, en accidentes, y ocasiones, cargos, y oficios del gobierno, civiles, y militares, cuidados, y desvelos de la razón de estado, despacho, y expediente de los negocios, y sus correspondencias, tan necesarias, y forçosas, que las tengo por el principal movimiento, acción y observancia de su dirección y el mejor modo de navegar al puerto de los buenos sucesos" $"$. Asimismo, incluye quince "Avisos graves y superiores que el Secretario Consegero debe dar à su Señor, para su gobierno, Casa, y Estados" "92, recomendaciones para los secretarios y los señores. Termina de un modo distinto al habitual, con un ánimo de desilusión, una despedida a "las amistades, negocios y pretensiones Cortesanas, y sus navegaciones, y con ochenta y seis años de desengaños se retira" 93 y dirigiéndole otro escrito a su hijo, también secretario.

En cuanto a la situación política de estos años, en 1615 la oposición al primer valido se acrecentaba y el duque de Lerma anunciaba en diferentes ocasiones su salida de la Corte. Aunque esta tardará aún dos años en producirse. Son numerosos los tratados de contenido político durante este tiempo, las críticas a Lerma entre 1615 y 1617 son implacables.

${ }^{90}$ Felipe II promulgó dos pragmáticas dedicadas a las cortesías la Premática, en que se da la orden y forma que se ha de tener y guardar, en los tratamientos y cortesias de palabra y por escrito: $y$ en traer coroneles, y ponellos en qualquier partes y lugares (Madrid, por Pedro Madrigal, 1586) y Premática en que se manda guardar la de los tratamientos y cortesias, y se acrecientan las penas contra los transgresores de lo en ella, y en esta contenido: y que se proceda de oficio no aviendo denunciador, o no prosiguiendo la causa: y la justicia que no lo hiziere tuviere cuidado de executarlo, pague de sus bienes penas que avian de pagar los condenados, y sea suspendido el oficio por dos años (Madrid, por Pedro Madrigal, 1594).

${ }^{91}$ Pérez del Barrio Angulo, Gabriel, Secretario y Consegero, cit. (n. 85), f. 2r.

${ }^{92}$ Ibíd., f. $34 \mathrm{v}$.

${ }^{93}$ Ibíd., f. $290 \mathrm{v}$ 
En este año de 1615 ve la luz la segunda parte del Quijote, una obra con cierto contenido político. Esa ansiada reforma del Estado se expresa desde el primer capítulo, Miguel de Cervantes relata como don Quijote, el cura y el barbero, conversando de aquello que "llaman razón de estado y modos de gobierno", se hacían "nuevos legisladores". Así probablemente es cómo se sintiera la mayoría de la sociedad cuando se afanaban con estos temas. Conocemos, además, por las palabras del barbero, cual era la opinión que existía sobre los arbitrios "tiene mostrado la experiencia que todos o los más arbitrios que se dan a su Majestad o son imposibles, o disparatados, o en daño del Rey o del reino" "4 . Además, en el capítulo siguiente, en afirmaciones de don Quijote a su escudero Sancho, encontramos una crítica implícita a todos aquellos aduladores que rodeaban al monarca: "que de los vasallos leales es decir la verdad a sus señores en su ser y figura propia, sin que la adulación la acreciente u otro vano respeto la disminuya; y quiero que sepas, Sancho, que si a los oidos de los principes llegase la verdad desnuda, sin los vestidos de la lisonja, otros siglos correrían, otras edades serían tenidas por más de hierro que la nuestra, que entiendo que de las que ahora se usan es la dorada"95.

Este mismo año, con la corte escindida en facciones políticas, como vimos anteriormente, el franciscano e "intelectual de la oposición a Lerma" ${ }^{6}$, fray Juan de Santa María publica Tratado de Republica, y policía christiana. Para Reyes y Príncipes: y para los que en el gobierno tiene sus vezes, en Madrid. Esta fue una obra que recibió buena acogida, en 1617 la volvió a publicar en Barcelona y en 1619 en Valencia, y más tarde en Lisboa y Nápoles. Tomás y Valiente la define como "un libro claro y bien escrito, con maneras sencillas y poco contaminadas aún del farragoso artificio del barroco" 97 . Maravall, por su parte, destaca que es el autor político que mantiene una postura más extrema, pues sostiene que el monarca que no respeta las decisiones adoptadas por el Consejo se adentra en la tiranía ${ }^{98}$. Santa María denuncia que aquellos que ocupan los oficios públicos no eran, en su mayoría, cumplidores en sus puestos, sino que ocupan esos cargos por vanidad, codicia, intereses crematísticos, avidez de poder o un modo de lograr inmunidad. Supone una cruenta crítica a Lerma y sus partidarios. Resalta la importancia que tiene el hecho de que el monarca escoja a las personas más virtuosas: "ministros trabajadores a su Republica. Ministros de confiança, de zelo, y de virtud conocida, que les quadre el nombre de consejeros, y no de palabreros" 99 . Este eclesiástico hace referencia también a esa problemática a la que Pérez del Barrio hizo alusión, a cómo por aquel entonces el empleo del término de secretario se había extendido, no contaba con unos límites definidos, y ello había provocado en palabras de

\footnotetext{
${ }^{94}$ Cervantes SaAvedra, Miguel de, Don Quijiote de la Mancha, 1615 [ed. utilizada, Madrid, Espasa Calpe, 1996], segunda parte, capítulo I, pp. 309 y 310.

${ }^{95}$ Ibíd., segunda parte, capítulo II, p. 318.

${ }^{96}$ Feros, Antonio, El Duque de Lerma, cit. (n. 57), p. 425.

${ }^{97}$ Tomás y Valiente, Francisco, Los validos, cit. (n. 58), p. 143.

${ }^{98}$ Maravall, José Antonio, La teoría, cit. (n. 11), p. 288.

${ }^{99}$ Santa María, Juan de, Tratado de Republica, y policía christiana. Para Reyes y Príncipes: y para los que en el gobierno tiene sus vezes. Compuesto por..., Religioso Descalço, de la Prouincia de San Ioseph, de la Orden de nuestro glorioso Padre San Francisco (Barcelona, por Sebastian de Cormellas y a su costa, 1617), f. 37 v.
} 
Santa María que se adjudicarán este vocablo "por lisonja de litigantes" "a los que ni guardan secreto, ni tratan negocios que le requieran". Por ello reivindica que no se mal utilice la denominación de este oficio, pues no se debe otorgar "la honra, y el titulo a quien no le viene de oficio". Como consecuencia de hallarse los cargos de la monarquía en manos de personas caracterizadas por su falta de competencia, este escritor dedica diversos capítulos de su obra a la elección de estas personas y a las cualidades que debían poseer para ocupar tales puestos.

En estos años, cuando la oposición al duque de Lerma se acrecienta, Santa María se cuestiona sí los reyes deben o no tener privados. Afirma que esta es una cuestión compleja puesto que privado es un "amigo particular". Pero claro, el autor en este Tratado de República, sostiene que la amistad tiene que ser entre iguales, por lo que esta no podría surgir entre el rey y sus vasallos o criados. Aunque más tarde puntualiza que cuando se trata de personas virtuosas, prudentes y eruditas, la desigualdad llega a desaparecer "porque la virtud tiene esa excelencia, que del polvo de la tierra levanta, y engrandece a los hombres de tal manera, que se igualen, y tengan asiento al lado de los grandes Principes". Santa María considera que los privados pueden tener orígenes diferentes, y hay que diferenciar dos tipos de amistad y de amor. Hay un amor amicitie y otro amor concupiscentie, el primero caracterizado por ser un sentimiento sincero, y el segundo por ser interesado. Además, alerta de un peligro: la privanza corrompe, conforme la relación entre el monarca y el privado es más estrecha, frecuentemente, se hace más desmerecedor de ella.

Otra cuestión relevante es la conveniencia de que el rey cuente con uno o más privados. Si se concibe al privado como una persona que trabaja, alerta al monarca de lo necesario para la nación y siempre trata de alcanzar el bien común de la monarquía, se deduce que lo más conveniente es que el rey disponga de más de uno. Ello beneficiaría tanto al soberano, que contaría con más colaboradores, como a los privados, que, al ver la existencia de competencia, les impulsaría a poner mayor diligencia en sus tareas. De esta serie de consideraciones se puede inferir que el franciscano Santa María de un modo tácito disiente de la figura del valido, en esos momentos Lerma, pues llega a aconsejar al monarca que se desaliente con aquellos que le recomendaran lo contrario a lo anteriormente afirmado, pues ello sólo verifica el anhelo de ser el dueño "absoluto de su voluntad"100.

Y si tenemos en cuenta, que estos son unos tiempos de gran corruptela, no es llamativo que los últimos capítulos de esta obra estén dedicados a la relación rey-privado, a determinar que a los oficios, como los de justicia, no deben acceder familiares y allegados de los privados, pues ello causa un grave daño al bien público. Es distinto en lo relativo a los oficios que no se dedican ni al gobierno ni a la justicia, es decir, los de gracia. Estos sí podrían ser susceptibles de ser concedidos a esas personas, pero estos cargos son de escasa relevancia.

Así, nos aproximamos a los años de 1617 y 1618 que son un auténtico hervidero en la Corte. Todos los acontecimientos anteriores tienen un corolario: tras veinte años, el hombre más poderoso de la monarquía, el duque de Lerma,

${ }^{100}$ Por todos, Santa María, Juan de, Tratado de Republica, y policía christiana, cit. (n. 99), ff. $178-214 \mathrm{v}$. 
se marcha al exilio. Ello se refleja en la literatura, pues tal circunstancia creaba el ambiente más propicio para que se publicaran obras de contenido político. Por otra parte, estos tratados no son opiniones individuales, sino que plasman las ideas de las distintas facciones políticas del momento. La preocupación sobre qué pasaría tras dejar el poder Gómez de Sandoval, fue generalizado en toda la monarquía, son publicados varios tratados relevantes y en diferentes reinos: Castilla, Valencia o Portugal.

En 1617, el monje cartujo de Portacaeli, Juan de Madariaga publica en Valencia Del Senado y de su Príncipe. Esta obra se compone de cuarenta y cuatro capítulos, en los que a diferencia de las obras que hemos visto anteriormente, Madariaga no se refiere a privados, validos o secretarios, sino al senado y los senadores, a los que configura. Al igual que en otros escritos se previene al monarca de los malos consejeros, incluyendo, incluso, un capítulo dedicado a las sanciones que habrían de imponérseles. Es al rey a quien le corresponde enjuiciar y decidir cuál es el mejor parecer que les ofrecen los senadores cuando lo aconsejan. Por ello el autor dedica gran parte de su obra a las condiciones que necesitan estos personajes. Incluye una apreciación que no muchos escritores señalan, y es el rechazo de la venalidad de los cargos. Defiende que para detentar oficios como los de gobernadores o regidores no era preciso el estudio de leyes, ser letrado, bastaba con que fuera "hombre de capa y espada"101, pues el que se prefiriera a los letrados para cuestiones de gobierno causaría un enorme descontento.

En este mismo año de 1617, se publica Excelencias de San Juan Bautista ${ }^{102}$, que redactó el doctor, alcalde de casa, corte y corregidor de Toledo, Gregorio López Madera. Esta obra ha sido caracterizada por Bermejo Cabrero como "extensa y amazacotada, de difícil lectura, configurada a modo de glosa o explicación de textos de la Sagrada Escritura" ${ }^{103}$. Aborda cuestiones políticas, en concreto la institución del secretario del rey, y lo hace a través de textos bíblicos. San Juan Bautista es presentado como una alegoría, pues dice de él que es el "Secretario de Dios y el mayor de los Secretarios"104. Dejando a un margen el contenido religioso, López

${ }^{101}$ Madariaga, Juan de, Del Senado y de su Príncipe. Por Fray..., Monge de la Cartuxa de Portace (Valencia, imprenta de Felipe Mey, junto a San Esteuan, 1617), p. 277.

${ }^{102}$ El empleo de este recurso literario, la alegoría de San Juan Bautista, ya fue utilizada por Lope de Vega en un auto histórico, político y religioso, escrito con motivo de las nupcias de Felipe III y su hermana Isabel Clara Eugenia, Bodas entre el alma y el Amor divino, que incorporó al final del libro II de la novela bizantina Elperegrino en su patria. En este auto San Juan Bautista ejemplifica a Lerma, por ello Feros considera que la obra "trata de legitimar la existencia del favorito sacralizando su rol”, en Feros, Antonio, El Duque de Lerma, cit. (n. 57), pp. 193 y 194. Véase Vega y Carpio, Lope de, El peregrino en su patria (Barcelona, en casa Sebastian de Cormelllas, 1605), f. 94.

${ }^{103}$ Bermejo Cabrero, José Luis, Estudio preliminar, en López Madera, Gregorio, Excelencias de la monarquía y reino de España (Madrid, Centro de Estudios Políticos y Constitucionales, 1999).

${ }^{104}$ López Madera, Gregorio, Excelencias de San Juan Bautista (Toledo, imprenta de Bernardino de Guzmán, 1617), f. 57v. 
Madera pone de manifiesto la grandeza de este cargo, "le pertenece mas que a todos, por su oficio consultarle a boca, y encomendársele los mayores secretos del Reyno" 105 .

Otra obra relevante que fue editada, en la imprenta de Luis Sánchez, donde ya imprimieron sus obras Gabriel Pérez del Barrio y Bermúdez de Pedraza, en 1617, fue "Consejo i Consejero de Principe" de Lorenzo Ramírez de Prado, como miembro del Consejo de Su Magestad en el real reino de Nápoles y dirigida al duque de Lerma. Tratado que parte de aforismos políticos de Juan de Chokier, los cuales traduce y comenta. En esta obra se les da mayor protagonismo a las virtudes, y requisitos que deben gozar los secretarios y consejeros, deberán contar con bienes tanto naturales como adquiridos. Así como que "sean escogidos los de Mediano Ingenio, no los de mui grande, i agudo", pues estos "se pierden, i desvanecen"106.

En Lisboa Juan Fernández Abarca, contador del rey de la artillería del reino de Portugal, en 1618 manda imprimir la obra: Discurso de las partes y calidades con que se forma un buen secretario. Con catorze capitulos, que debe guardar para su entereza. Con una recapitulación de el numero que ay de cartas misivas para su ejercicio. $Y$ de los géneros que son y las que tocan a cada uno. $Y$ un tratado, de las partes que an de tener los criados, que an de servir en las casas de los señores.

Este tratado está dedicado a la figura del secretario, cuya distinción más elevada es ejercer sus funciones junto al monarca, desempeñará tareas de gran relevancia para el Estado. De esta suerte, comienza la obra especificando que excelencias se precisan para ser un buen secretario, vale decir, entre otras, detentar entendimiento, ser leído de historias tanto humanas como divinas, sabedor de latín y ser una persona experimentada en esas labores, pues ello puedo ser beneficioso, le "pueden servir en esta facultad, para sostener un estado, y acrecentar el poder, procurando el bien y huir del mal'107, por lo que sería conveniente que no fuera muy joven, a no ser que su talento fuera extraordinario.

De tal modo, Fernández Abarca indica lo necesario de que el secretario "como caudillo fiel, refiera lo que passa, y sepa significar la demostracion de la intención, con que cada uno ha propuesto y hablado, y procurar inclinar la de su Principe a lo mejor y mas conveniente". Además, el buen secretario, ha de ser como "un segundo confessor, esencial y confidente ministro" 108 .

Así tras caracterizar al secretario, en distintos capítulos se detalla el modo en

${ }^{105}$ Ibíd., f. 59 r.

${ }^{106}$ Ramírez de Prado, Lorenzo, Consejo i Consejero de Principe de Don..., del Consejo de Sv Mag. En el Real Reino de Napoles. Al exmo. Señor Don Francisco Gomes de Sandoval i Rojas Dvque de Lerma, Marques de Denia, del Consejo de Estado del Rei Don Filipe III. N.S. (Madrid, por Luis Sánchez, 1617), p. 6.

${ }^{107}$ Fernández Abarca, Juan, Discurso de las partes y calidades con que se forma un buen secretario. Con catorze capitulos, que debe guardar para su entereza. Con una recapitulación de el número que ay de Cartas misibas para su ejercicio. $Y$ de los generos que son y las que tocan a cada uno. Y un tratado, de las partes que an de tener los criados, que an de serbir en las casas de los señores. Compvesto por..., Contador de el Rey nuestro señor, de la Artilleria de el Reyno de Portugal. Dirigido a Don Ivan de Mendoza. Marques de la Hinojosa, Gentil hombre de la Camara de el Rey nuestro señor, y de su Consejo de guerra, Capitan General de la Artilleria de España, y sus Islas (Lisboa, por Pedro Craesbeeck, 1618), f. 15v.

${ }^{108}$ Ibíd., ff. 18v. y 26r. 
que debe comportarse y realizar su labor: con templanza, forma de tratar con los súbditos, de despachar o cómo serán las audiencias. Tras todo lo cual la segunda parte del tratado se dedica a formularios, como ya lo vimos en la de obra de Pérez del Barrio, modelos de cartas, de textos de carácter judicial, narrativa..., en definitiva, de diferentes géneros. Finalizando estos discursos con aquellas cualidades que deben tener los criados de las casas de los señores, como el camarero, el caballerizo o el contador.

En este año de 1618, con la marcha de Lerma y Felipe III enfermo, comienza otra guerra en palacio: la lucha por el poder. Domínguez Ortiz califica este periodo como d e c i s i v o ${ }^{109}$ : El duque de Lerma es sustituido en el valimiento por su hijo el duque de Uceda; se crea la Junta de Reformación tras solicitarlo las Cortes de Castilla, con la finalidad de paliar las numerosas desdichas que afectaban a la monarquía. Y en Europa, daría comienzo lo que serían treinta años de dura contienda, debido a que los protestantes bohemios se rebelaron contra el emperador austriaco.

La situación social, económica y política se refleja en los testimonios de la época. El doctor y catedrático Sancho de Moncada califica el estado de España a principios de 1619 como "lastimosisimo" ${ }^{110}$, la presenta en peligro, con una población escasa debido a causas diversas como son las pestes, las expulsiones, las guerras de Nápoles, Sicilia, Milán... Pero además de escasa era pobre, nos describe como la gente huía para "buscar de comer", se encontraba "muriendo de hambre"111. Para Moncada el auténtico origen de esta situación se hallaba en la política comercial que seguía el reino, sin capacidad de producir productos manufacturados, y cuyas materias primas y la plata se exportaban a países extranjeros ${ }^{112}$. Varias centurias después vemos la coincidencia del diagnóstico que hizo Moncada en el siglo XVII, con las investigaciones de Domínguez Ortiz en el XX, que comprobó como en España la economía se encontraba sometida a la política exterior a diferencia de otros estados, como Inglaterra y Holanda, donde la política está dirigida por la economía ${ }^{113}$.

De esta situación se hace responsable al duque de Lerma, por su desastrosa política, tanto interior como exterior, que dio lugar a la decadencia de España, surgiendo una dura oposición contra él auspiciada por la propia reina Margarita de Austria, que logró que el rey lo sustituyera por el duque de Uceda.

En 1620 ve la luz en Madrid la primera edición de El Secretario del Rey, escrito por el jurista granadino Francisco Bermúdez de Pedraza. Un tratado que el autor dirige al rey, Felipe III, para reivindicar la figura del secretario del rey, que aunque carente de institucionalización él la configura. Esta obra constituye una crítica implícita a los validos; el propio título es una reprobación de este régimen, pues

${ }^{109}$ Domínguez Ortiz, Antonio, Tres milenios de historia, cit. (n. 10), p. 164.

${ }^{110}$ De Moncada, Sancho, Restauración politica de España y deseos públicos (Madrid, 1619). Hemos utilizado la edición de 1746.

${ }^{111}$ Ibíd., p. 50.

${ }^{112}$ Ibíd., p. 9.

${ }^{113}$ Domínguez Ortiz, Antonio, Crisis y decadencia de la España de los Austrias (Barcelona, Ariel, 1984), p. 6. 
se dirige a una figura que en esos momentos ya había dejado de ser la institución preeminente que había sido en el pasado.

El Secretario del Rey se incluye dentro del periodo 1618-1621 (exilio de Lerma y fallecimiento de Felipe III) calificado de "sacudida espiritual e intelectual" 114 , por la pretensión de salir de la situación que vive el Reino. Esto nos hace conjeturar que Bermúdez de Pedraza redactara esta obra tras la caída del duque de Lerma o cuando esta se presagiaba inminente; la expulsión del valido de la Corte podía ser un momento propicio para el resurgir de los secretarios y volver a la forma de gobierno de los anteriores reinados. Es en la necesidad de su cargo de donde emerge su grandeza. De tal modo, que para Bermúdez es sumamente importante a quien se designe y qué cualidades deberá poseer. Y en ello se justifica el que los restantes discursos, salvo el último, se dediquen a desgranar estas cuestiones.

Por último, nos vamos a referir de nuevo a Brancalasso, en su obra además de ocuparse de la Corte, como ya hemos visto, tiene un fuerte protagonismo los privados, hasta el extremo de constituir una fuerte crítica a su figura. No obstante, se presentan como un mal necesario, el autor emplea un tono irónico cuando afirma que sería inconcebible su no presencia en la burocracia, si no estuvieran en la Corte este podría llegar a ser un paraíso terrenal. Se trata de unos miembros de la monarquía que alcanzan las cotas de poder más altas, pero que por ello la caída es más fuerte: "son los priuados leuantados, y subidos hasta el cielo para hazer lastimosa cayda hasta el abismo". De hecho, el capítulo primero de su libro lo titula como Lástima de los privados, en el se refiere a Álvaro de Luna, privado del rey Juan II de Castilla, a quien el propio monarca ordenó que le cortaran la cabeza y de quien afirmaba Brancalasso que aún en su tiempo se oían lagrimosas canciones de su privanza. Define la privanza como: "una singular excelente, y ordenada afçion que soberano Señor en su tanto tiene à alguna persona por proprios merecimientos, ó por servicios de antepassados"; "Minotauro que está dentro del laberinto, y traga los que á el llegan". Y apostilla que "la privança de este siglo no es otra cosa, que vna perpetua comedia, y los hombres representan en ella diferentes personajes". La obra de Brancalasso contiene duras sentencias contra los privados: "Vno de los mayores males que lleua consigo la privança del mundo, es que para conseruarse en su ser, embidia los beneméritos de la republica, y procura alexarlos de los ojos de su Rey, y no saue que en ello esta escondida su pobreza que presto le vendrá". "Piensa el priuado que la fruta de su priuanza es regalo, honra, señorio, respeto y mando, y no echa de ver que todo es miseria", asevera que los privados de su tiempo "perecen lastimosamente”. Además, critica como los privados que abusan de su poder no se veían sometidos a la justicia: "La pena de las leyes no aftige si no es à los pobres; pasa como volando por las casas de los Priuados, que todo lo pisan, todo lo hollan". Sin embargo, Brancalasso elabora una guía sobre el comportamiento del privado para ganarse la voluntad del propio rey, y todo aquel que le asiste, tales como la reina, criados, allegados, cortesanos, ministros del monarca, nobleza, eclesiásticos, embajadores ${ }^{115}$.

\footnotetext{
${ }^{114}$ Feros, Antonio, El Duque de Lerma, cit. (n. 57), p. 445.

${ }^{115}$ Brancalasso, Julio Antonio, Libro Labirinto de Corte, cit. (n. 28), pp. 2-39.
} 


\section{CONCLUSIONes}

A lo largo de este trabajo hemos realizado un análisis de la literatura jurídicopolítica que vio la luz a lo largo de los siglos XVI y XVII. Época que es conocida como el Siglo de Oro de las letras, y en la que fueron prolijos los tratados jurídicopolíticos dados a la imprenta. El hecho de haber analizado diversos libros de la Edad Moderna nos ha permitido valorar la exuberancia de este tipo de textos, se ha puesto de manifiesto como la mayoría de ellos compartían ciertos aspectos, desde su apariencia estética hasta la temática, por lo azaroso de la época muchos de los escritores mostraron su preocupación por los asuntos de la burocracia de la monarquía. En aras de realizar una mejor comprensión sobre estos asuntos y poner de manifiesto qué tratamiento recibían estas cuestiones por parte de los escritores, muchos de ellos burócratas, hemos analizado sucesivas fuentes primarias, que constituyen una fuente ineludible para el estudio de la Edad Moderna y un reflejo del devenir político, económico y social del momento.

Hemos fijado nuestra atención, en primer lugar, sobre el tratamiento que ha recibido la Corte y cómo los tratadistas la definían y presentaban como un lugar perverso, libidinoso... Es cierto que la definición etimológica de la palabra Corte puede ser más o menos acertada, pero se corrobora que ha sido constante la pretensión de definirla, encontrando precedentes desde las Partidas de Alfonso X El Sabio. En segundo lugar, nos hemos ocupado de examinar la preocupación que sentían los escritores por la figura que se sitúa junto al rey, los privados, validos y ministros. Es destacable como muchos de los tratadistas no se atrevían a criticar abiertamente a la institución, pero lo hacían de un modo implícito o tácito a través de sus escritos, reivindicando otros oficios o estableciendo una guía de comportamiento, o indicar las cualidades que debían ostentar el perfecto burócrata.

\section{BibLIOGRAFÍA}

Bennassar, Bartolomé, La monarquía española de los Austrias. Conceptos, poderes y expresiones sociales (Salamanca, Universidad de Salamanca, 2006).

Bermejo Cabrero, José Luis, Estudio preliminar, en López Madera, Gregorio, Excelencias de la Monarquía y Reino de España (Madrid, Centro de Estudios Políticos y Constitucionales, 1999).

Bermúdez de Pedraza, Francisco, Hospital Real de la Corte, por Don..., Canonigo y Tesorero de la Santa Iglesia de Granada. A D. Francisco Marin y Rodezno Canonigo de la S. I. de Toledo, Inquisidor de Granada (Granada, 1645).

BleznicK, Donald W., Los conceptos politicos de Furio Ceriol, en Revista de Estudios Políticos, 149 (1966), pp. 25-46.

Brancalasso, Julio Antonio, Libro Labirinto de Corte con los diez predicamentos de cortesanos. Dos libros en los quales estan comprehendidos todos los bienes, y males que pueden, y suelen acontecer en las Cortes de Principes à los que sigue. Y se dan diferentes modos de salir felizmente del Laberinto para gloria de Dios, y con honras, y riquezas del mundo, como tambien para fundar vna Corte Real. Con los avisos necesarios para ganar, conseruar la gracia de los mesmos Principes, y de todos los generos de personas que en qualquiera manera tratan con ellos. Resumidos de los Autores politicos Catholicos 
que hastagora han escrito en materia de estado, y de buen gouierno. Por el Doctor..., sacerdote natural de la Ciudad de Tursi. Vn tomo llamado Labirinto de Corte (Nápoles, por Juan Bautista Gargano, y Lucrecio Nucci Empressores, 1609).

Caporossi, Olivier, La Babilonia del crimen o la nueva Roma de la policía cristiana: el discurso sobre la decadencia y la reformación de la Corte en la primera mitad del siglo XVII (1597-1645), en Aranda Pérez, F.J. (coord.), La declinación de la monarquía hispánica en el siglo XVII (1597-1645) (Universidad de Castilla-La Mancha, 2004), pp. 845-861.

Castillo de Bovadilla, Jerónimo, Politica para Corregidores, y Señores de Vassallos, en tiempo de paz, y de guerra. Y para Juezes Ecclesiasticos y Seglares y de Sacas, Aduanas, $y$ de Residencias, y sus Oficiales: y para Regidores, y Abogados, y del valor de los Corregimientos, y Goviernos Realengos, y de las Ordenes, Autor el Licenciado..., del Consejo del Rey Don Felipe III nuestro Señor, y su Fiscal en la Real Chancilleria de Valladolid (en Amberes, en casa de Iuan Bautista Verdussen, Impressor y Mercader de Libros, 1704 [1ª ed., Madrid, 1597], edición facsímil, con Estudio preliminar por Benjamín González Alonso, Instituto de Estudios de Administración Local, Madrid, 1978).

Cervantes Saavedra, Miguel de, Don Quijiote de la Mancha, 1615 (ed. utilizada, Madrid, Espasa Calpe, 1996).

Covarruvias Orozco, Sebastián de, Tesoro de la lengva casteñana. Española. Compvesto por el Licenciado Don..., Capellan de su Magestad, Maestrescuela y Canonigo de la Santa Yglesia de Cuenca, y Consultor del Santo Oficio de la Inquisición. Dirigido a la Magestad Catolica del Rey Don Felipe III nuestro señor (Madrid, con privilegio, por Luis Sanchez, impressor del Rey N. S., Año del Señor, 1611).

De Camos, Marco Antonio, Microcosmia y Gobierno Universal del Hombre christiano, para todos los estados y qualquiera de ellos. Dirigido a Don Antonio de Cardona, Duque de Sessa y Soma, del Consejo del Rey nuestro Señor, y por su Magestad Embaxador de España en Roma. Va por Dialogos dividido en tres partes en la primera se trata de las Personas Reales, y de su gouierno de paz y guerra, consejos, y ministros. En la Segunda, del gouierno Politico, Magistrados, y Personas ocupadas en ellos: y de la Economia y estados a la Republica necesarios. En la Tercera y vultima dela Monarchia Ecclesiastica y Personas de ese estado, y Religioso. Compuesto por el maestro..., prior del Monasterio de S. Agustín de Barcelona. Con quatro Indices necesarios y copiosos (Barcelona, en el Monasterio de Sancto Agustin, por Pablo Malo, 1592).

De Guevara, Antonio, Aviso de privados, y doctrina de Cortesanos. Compuesto por el Illustre y Reuerendissimo señor don..., Obispo de Mondoñedo, Predicador, y Choronista, $y$ del Consejo de su Magestad. Dirigido al Illustre señor don Francisco de los Cobos, Comendador mayor de Leon, del consejo de estado de su Magestad. Dirigido al Illustre señor don Francisco de los Cobos, Comendador mayor de Leon, del consejo de estado de su Magestad, (Barcelona, Hieronymo Margarit, 1612).

- Menosprecio de Corte, y. alabanza de aldea, en el qual se tocan muchas, y muy buenas doctrinas, para los hombres que aman el reposo de sus casas, y aborrecen el bullicio de las Cortes, copilado por el Illmo. Y Rmo. Sr. Don..., Obispo de Mondoñedo, Predicador, y Choronista y del Consejo de su Magestad. Dirigido al muy alto y Poderoso Rey de Portugal, Don Juan el Tercero deste nombre. (Quinta impression, Madrid, con licencia, por Juan Valentino, año de 1735).

De Moncada, Sancho, Restauración política de España y deseos públicos (Madrid, 1619). Hemos utilizado la edición de 1746. 
De Quevedo, Francisco, La política de Dios, capitulo XXI, edición utilizada: Obras de D. Francisco de Quevedo Villegas, vol. III (Madrid, por D. Joachin Ibarra, 1752).

Deleito y Piñuela, José, Sólo Madrid es Corte (La capital de dos mundos bajo Felipe IV (Madrid, Espasa-Calpe, 1963).

Domínguez Ortiz, Antonio, Crisis y decadencia de la España de los Austrias (Barcelona, Ariel, 1984).

- Tres milenios de historia, (Madrid, Marcial Pons, 2001).

Dubet, Anne y Sabatini, Gaetano, Arbitristas: Acción política y propuesta económica, en Martínez Millán, José y Visceglia, María Antonietta (dirs.), La monarquía de Felipe III: La Casa del Rey (Madrid, Fundación Mapfre, Instituto de Cultura, 2008).

ElliotT, John, El Conde Duque de Olivares, sociedad y Estado en el siglo XVII (Historia, 1979; Barcelona, Editorial Crítica, 1991).

Escudero López, José Antonio, Los Secretarios de Estado y del Despacho (Madrid, Estudios de Historia de la Administración, Instituto de Estudios Administrativos, 1969).

Felippe, Bartolomé, Tractado del Consejo y delos consejeros delos Principes, compuesto por el Doctor...: Dirigido al muy alto y serenissimo señor Cardenal Alberto Legado y Archiduque Daustria, (Coímbra, impresso en casa de Antonio de Mariz, impresor de la Vniversidad, 1584).

FERnÁNDEZ AbARCA, Juan, Discurso de las partes y calidades con que se forma un buen secretario. Con catorze capitulos, que debe guardar para su entereza. Con una recapitulación de el número que ay de Cartas misibas para su ejercicio. $Y$ de los generos que son y las que tocan a cada uno. Y un tratado, de las partes que an de tener los criados, que an de serbir en las casas de los señores. Compvesto por..., Contador de el Rey nuestro señor, de la Artilleria de el Reyno de Portugal. Dirigido a Don Ivan de Mendoza. Marques de la Hinojosa, Gentil hombre de la Camara de el Rey nuestro señor, y de su Consejo de guerra, Capitan General de la Artilleria de España, y sus Islas (Lisboa, por Pedro Craesbeeck, 1618).

Fernandez Navarrete, Pedro, Aviso de privados y doctrina de cortesanos. Compuesto por el Illustre y Reverendisimo señor don..., Obispo de Mondoñedo, Predicador, y Chronista $y$ del Consejo de su Magestad. Es obra muy digna de leer, y aun muy necessaria de a la memoria encomendar, (Pamplona, impresso con licendia de su magestad, por Thomas Parralis, 1579).

- Conservación de Monarquias y Discursos políticos sobre la gran consulta que el Consejo hizo al Señor Rey don Filipe Tercero al presidente, y Consejo Supremo de Castilla, (Madrid, En la Imprenta Real, 1626).

- Conservacion de Monarqvias y Discvrsos políticos sobre la gran Consulta que el Consejo hizo al Señor Rey don Filipe Tercero al Presidente y Consejo Supremo de Castilla, por el Licenciado..., Canonigo del a Iglesia Apostolica de Señor Santiago Capellan y So de sus Magestades y Altezas. Consultos del Santo Oficio de la Inquisicion (en Madrid, con privilegio, en la Imprenta Real Año, 1626).

Feros, Antonio, El Duque de Lerma. Realeza y privanza en la España de Felipe III (Madrid, Marcial Pons, 2002).

Furió Ceriol, Fadrique, El Concejo y consejeros del Príncipe. Obra de..., que es el libro primero del quinto Tratado dela institución del Principe (Amberes, en casa de la Biuda de Martin Nucio, 1559).

García Guerra, Elena María, Moneda y arbitrios. Consideraciones del siglo XVII (Madrid, Departamento de Publicaciones del Consejo Superior de Investigaciones Científicas, 2003). 
García Marín, José, La burocracia castellana bajo los Austrias (Sevilla, Ediciones del Instituto García Oviedo, Universidad de Sevilla, 1976).

GiL Pujol, Xavier, La razón de Estado en la España de la Contrarreforma. Usos y razones de la política, en La razón de Estado en la España Moderna (Valencia, Publicaciones de la Real Sociedad Económica del país, 2000).

González Dávila, Gil, Monarquía de España. Historia de la vida y hechos del inclito monarca, amado y santo D. Felipe Tercero. Obra posthuma del maestro..., cronista de los Señores Reyes D. Felipe III y IV, y mayor de las dos Castillas y de las Indias. Publicala Don Bartholome Ulloa, mercader de libros (Madrid, por D. Joachin de Ibarra, 1771).

- Teatro de las grandezas de la Villa de Madrid Corte de los Reyes Católicos de España (Madrid, 1623).

GonzÁlez de Cellorigo, Martín, Memorial de la politica necesaria y útil restauración a la República de España, y estados de ella y del desempeño universal de estos Reynos. Dirigido al Rey Don Philippe III, nuestro señor. Por el Licenciado..., Abogado de la Real Chancilleria, y del Santo Officio de la ciudad de Valladolid (Valladolid, por Juan de Bostillo, 1600).

Goñi Gaztambide, José, El licenciado Pedro Fernández Navarrete su vida y sus obras (1564-1632), en Berceo, 97 (1979), pp. 27-48.

Gracián Dantisco, Lucas, Galateo español (Madrid, Luis Sanchez, 1599).

Gracián Lorenzo, Obras de Lorenzo Gracian. Tomo primero que contiene El criticon, primera, Segunda y Tercera parte: Y el Heroe (en Madrid, en la Imprenta de Pedro Marin, año de 1773, a costa de la Real Compañía de Impresores, y Libreros de el Reyno).

Gracián, Baltasar, Óraculo manual y arte de prudencia (Madrid, CSIC, 1954).

Gutiérrez NieTo, Juan Ignacio, El pensamiento económico, político y social de los arbitristas, en Historia de España Menéndez Pidal, XXVI (1): El siglo del Quijote (15801680). Religión filosofía, ciencia, (Madrid, Espasa Calpe, 1986), pp. 235-354.

LiñÁn y Verdugo, Antonio, Guia y avisos de forasteros, a donde se les enseña a huir de los peligros que ay en la vida de Corte; y debaxo de nouelas morales, y exemplares escarmientos, se les auisa, y aduierte de como acudirán a sus negocios cuerdamente, por el licenciado Don..., (Madrid, con privilegio, por la viuda de Alonso Martin, 1620).

López Madera, Gregorio, Excelencias de San Juan Bautista (Toledo, imprenta de Bernardino de Guzmán, 1617).

Madariaga, Juan de, Del Senado y de su Príncipe. Por Fray..., Monge de la Cartuxa de Portace (Valencia, imprenta de Felipe Mey, junto a San Esteuan, 1617).

MaraVall, José Antonio, Estado moderno y mentalidad social, siglos XV a XVII (Madrid, Ediciones de la Revista Occidente, 1972), II.

- La teoría española del Estado en el siglo XVII (Madrid, Instituto de Estudios Políticos, 1944).

Martínez Millán, José, Introducción. La Monarquia de Felipe III: Corte y Reinos, en Martínez Millán, José y Visceglia, María Antonietta (dirs.), La monarquía de Felipe III: La Casa del Rey (Madrid, Fundación Mapfre, Instituto de Cultura, 2008).

Menéndez PIdal, Ramón, El P. las Casas y Vitoria con otros temas de los siglos XVI y XVII, (Madrid, Espasa-Calpe, 1966).

Moralejo Álvarez, José Luis, Introducción en TáctTo, Historias (Madrid, Akal, 1990). Murillo Ferrol, Francisco, Saavedra Fajardo y la politica del Barroco (Madrid, Instituto de Estudios Políticos, 1957). 
NúNÉE de CASTRO, Alonso, Libro histórico político, solo Madrid es Corte, y el cortesano en Madrid, (Madrid, por Domingo García Morrás, 1669).

Pérez del Barrio Angulo, Gabriel, Direccion de Secretarios de Señores, y las materias, cuydados, y obligaciones que les tocan, con las virtudes de que se han de preciar, estilo, y orden del despacho y expediente, manejo de papeles de ministros, formularios de cartas, prouisiones de oficios, y un compendio en razon de acrecentar estado, y hazienda, oficio de Contador, y otras curiosidades que se declaran en la primera hoja. Por..., Secretario del Marques de los Velez, y Alcayde de la Fortaleza de su villa de Librilla. Dirigido al Marques de Cañete don Iuan Andres Hurtado de Mendoça (en Madrid, por Alfonso Martin de Balboa, año 1613).

Pérez del Barrio Angulo, Gabriel, Secretario y Consegero de Señores, y Ministros; cargos, materias, cuidados, obligaciones, y curioso Agricultor de quanto el Gobierno, y la Pluma piden para cumplir con ellas: El indice las toca, y están ilustradas con sentencias, conceptos, y curiosidades no tocadas, 1639. Hemos utilizado la edición de Madrid, por Mateo de Espinosa, 1667.

Rabell, Carmen R., Menosprecio de corte y alabanza de aldea: ¡critica lascasiana, propaganda imperialista o "best-seller"?, en Actas Irvine-92 [Actas de XI Congreso de la Asociación Internacional de Hispanistas] (Madrid, 1994), pp. 245-253.

Ramírez de Prado, Lorenzo, Consejo i Consejero de Principe de Don..., del Consejo de Sv Mag. En el Real Reino de Napoles. Al exmo. Señor Don Francisco Gomes de Sandoval i Rojas Dvque de Lerma, Marques de Denia, del Consejo de Estado del Rei Don Filipe III. N.S. (Madrid, por Luis Sánchez, 1617).

Rey Hazas, Antonio, Madrid: corte y literatura en la primera mitad del siglo XVII, en Martínez Millán, José y Visceglia, María Antonietta (dirs.), La monarquía de Felipe III: La Casa del Rey (Madrid, Fundación Mapfre, Instituto de Cultura, 2008), pp. 651-666.

Riaza Martínez-Osorio, Román, Historia de la literatura jurídica española, Madrid, 1930, en Interpretatio. Revista de Historia del Derecho de la Universidad Complutense de Madrid, 5 (1998), pp. 17-239.

Ribadeneyra, Pedro, Tratado de la religion y virtudes que debe tener el Principe Christiano, para gobernar y conservar sus Estados. Contra lo que Nicolas Maquiavelo y los Politicos deste tiempo enseñan. Escrito por el P..., de la Compañia de Iesus. Dirigido al Principe de España D. Filipe nuestro señor (Madrid, en la emprenta de Plantiniana, 1597).

Rivero Rodríguez, Manuel, Los consejos territoriales, en Martínez Millán, José y Visceglia, María Antonietta (dirs.), La monarquía de Felipe III: La Casa del Rey (Madrid, Fundación Mapfre, Instituto de Cultura, 2008), pp. 372-434.

Rojo Gallego-Burín, Marina, La literatura jurídico-política castellana y portuguesa de los siglos XVI y XVII, en Revista Jurídica Universidad Autónoma de Madrid, 33 (2016), pp. 233-249.

- El pensamiento jurídico y político de Francisco Bermúdez de Pedraza (1576-1655) (Madrid, Marcial Pons, 2018).

SaAvedra Fajardo, Diego, Idea de un príncipe politico-christiano por..., caballero de la Orden de Santiago (en Valencia, en la Oficina de Salvador Faulí, año 1801), II.

Santa María, Juan de, Tratado de Republica, y policía christiana. Para Reyes y Príncipes: y para los que en el gobierno tiene sus vezes. Compuesto por..., Religioso Descalço, de la Prouincia de San Ioseph, de la Orden de nuestro glorioso Padre San Francisco (Barcelona, por Sebastian de Cormellas y a su costa, 1617). 
Serrano SÁnchez, Carmen, Cartas al Papa: modelos epistolares en los manuales de correspondencia de los siglos XVI-XVII, en Via Spiritus. Revista de História da Espiritualidade e do Sentimento Religioso, 18 (2012), pp. 159-182.

Tierno Galván, Enrique, El tacitismo en las doctrinas politicas del Siglo de Oro, en Anales de la Universidad de Murcia, Murcia, 4 (4o trimestre, 1948), pp. 805-988.

Tomás y VAliente, Francisco, El gobierno de la monarquía y la administración de los reinos en la España del siglo XVII, en Historia de España, Ramón Menéndez Pidal, XXV: La España de Felipe IV (Madrid, Ed. Espasa-Calpe, 1982), pp. 1-214.

- Las instituciones situadas en el ámbito de la monarquía, en Historia de España, Ramón Menéndez Pidal, XXV: La España de Felipe IV (Madrid, Espasa- Calpe, 1982).

- Los validos en la monarquía española del siglo XVII. Estudio institucional (1 ${ }^{\mathrm{a}} \mathrm{ed}$., Instituto de Estudios Políticos, Madrid, 1963; Madrid, Siglo Veintiuno de España Editores, 1990).

Vega y Carpio, Lope de, El peregrino en su patria (Barcelona, en casa Sebastian de Cormelllas, 1605).

Villalva Álvarez, Joaquín, La presencia de Tácito en los Anales de quince días, de Francisco de Quevedo. Una visión tácita de España, en Norba. Revista de Historia, 17 (2004), pp. 205-223.

Williams, Patrick, El favorito del rey: Francisco Gómez de Sandoval y Rojas, V marqués de Denia y I duque de Lerma, en Martínez Millán, José y Visceglia, María Antonietta (dirs.), La monarquía de Felipe III: La Casa del Rey (Madrid, Fundación Mapfre, Instituto de Cultura, 2008), pp. 285-260. 